\title{
Characterization and tissue-specific expression patterns of the Plasmodium chabaudi cir multigene family
}

Petra Ebbinghaus and Jürgen Krücken ${ }^{*}$

\begin{abstract}
Background: Variant antigens expressed on the surface of parasitized red blood cells (pRBCs) are important virulence factors of malaria parasites. Whereas Plasmodium falciparum erythrocyte membrane proteins 1 (PfEMP1) are responsible for sequestration of mature parasites, little is known about putative ligands mediating cytoadherence to host receptors in other Plasmodium species. Candidates include members of the pir superfamily found in the human parasite Plasmodium vivax (vir), in the simian pathogen Plasmodium knowlesi (kir) and in the rodent malarias Plasmodium yoelii (yir), Plasmodium berghei (bir) and Plasmodium chabaudi (cir). The aim of this study was to reveal a potential involvement of cir genes in $P$. chabaudi sequestration.

Methods: Subfamilies of cir genes were identified by bioinformatic analyses of annotated sequence data in the Plasmodium Genome Database. In order to examine tissue-specific differences in the expression of cir mRNAs, RTPCR with subfamily-specific primers was used. In total, 432 cDNA clones derived from six different tissues were sequenced to characterize the transcribed cir gene repertoire. To confirm differences in transcription profiles of cir genes, restriction fragment length polymorphism (RFLP) analyses were performed to compare different host tissues and to identify changes during the course of $P$. chabaudi infections in immunocompetent mice.

Results: The phylogenetic analysis of annotated $P$. chabaudi putative CIR proteins identified two major subfamilies. Comparison of transcribed cir genes from six different tissues revealed significant differences in the frequency clones belonging to individual cir gene subgroups were obtained from different tissues. Further hints of difference in the transcription of cir genes in individual tissues were obtained by RFLP. Whereas only minimal changes in the transcription pattern of cir genes could be detected during the developmental cycle of the parasites, switching to expression of other cir genes during the course of an infection was observed around or after peak parasitemia.

Conclusions: The tissue-specific expression of cir mRNAs found in this study indicates correlation between expression of CIR antigens and distribution of parasites in inner organs. Together with comparable results for other members of the pir superfamily this suggests a role of cir and other pir genes in antigenic variation and sequestration of malaria parasites.
\end{abstract}

\section{Background}

Antigenic variation is a major characteristic of malaria parasites of the genus Plasmodium leading to severe and chronic infections in a variety of vertebrates. Malaria parasites have developed strategies to evade host immune responses by expressing a large and diverse repertoire of variant proteins on the surface of

\footnotetext{
* Correspondence: kruecken.juergen@vetmed.fu-berlin.de Institute for Parasitology and Tropical Veterinary Medicine, Freie Universität Berlin, Königsweg 67, 14163 Berlin, Germany
}

parasitized red blood cells (pRBCs) [1-4]. By rapidly switching between these antigens, the parasites avoid antibody-mediated immunity of the host thus enabling the parasites to proliferate in the host without being completely eliminated by the adaptive immune response. Furthermore, these surface antigens were proposed to be involved in adherence to endothelial cells causing sequestration of late trophozoites and schizonts in postcapillary venules in specific inner organs, which considerably contributes to severe pathology in the host [5-8].

\section{() Biomed Central}


In the most virulent human pathogen Plasmodium falciparum, the PfEMP1 protein family encoded by widely studied var genes was shown to be expressed at the surface of $\mathrm{pRBC}$ mediating the parasite binding to endothelial cells lining small blood vessels $[9,10]$. Several in vitro assays with $P$. falciparum revealed a tight regulation of the expression of the individual variant antigens by silencing, activation and mutually exclusive expression, thus only one variant protein is expressed in parasites at any given time [10-13]. By switching the expression to another variant, antigenic properties of the surface of pRBCs changes and the parasites prevent their complete clearance $[10,14]$. Typical waves of parasitaemia in persistent $P$. falciparum infections reflect the repeated switching between different members of the diverse repertoire of variant antigens [10].

Further variant surface antigens encoded by multigene families were found in several other Plasmodium species infecting humans, monkeys and rodents [4,15-17]. However, homologues of the var genes are not present in Plasmodium vivax or other malaria species [18], with exception of several var-like sequences from the chimpanzee parasite Plasmodium reichenowi [19], a close relative of $P$. falciparum.

The largest multigene family in Plasmodium genomes was described to be formed by the Plasmodium interspersed repeat (pir) genes [20,21]. The superfamily of pir genes constitutes the major variant surface antigen family in most Plasmodium species. They were found in the human pathogen P. vivax (vir) [22], in the simian parasite Plasmodium knowlesi (kir) [18] and in the rodent malaria species Plasmodium yoelii (yir), Plasmodium berghei (bir) and Plasmodium chabaudi (cir) $[15,17,23]$. Transcriptional changes of yir genes modulated by host immunity were reported in immunocompetent mice infected with $P$. yoelii [24]. In contrast to the exclusive expression of individual var genes and consecutive activation of different genes in P. falciparum, transcriptional profiling analyses in $P$. yoelii showed a simultaneous expression of a broad range of different yir genes within different intra-erythrocytic developmental parasite stages [25]. In a single parasite, however, only one to three yir transcripts were detectable. Cunningham and colleagues [25] concluded that antigenic variation in $P$. yoelii probably involves exposure of the immune system to many different YIR antigens and transcriptional switching takes place without any epigenetic memory. For the variant VIR proteins of the most widely distributed human malaria pathogen $P$. vivax, a similar differential expression in natural infections could also be detected [26] and for the cir genes of the rodent malaria species $P$. chabaudi antigenic switching in laboratory mice has already been described [15].
Although the PIR proteins were localised close to the surface of pRBCs infected with $P$. vivax, $P$. yoelii, $P$. berghei, and P. chabaudi [20,22,24,27], less is known about the role of PIR proteins in host/parasite interactions. For instance, a supposed correlation of antigenic variation of the PIRs with sequestration in inner organs has not yet been analysed. In P. falciparum, adherence of pRBCs to different host receptor such as CD36, ICAM1 or chondroitin-sulfate A (CSA) is mediated by the major variant protein PfEMP1 $[6,8,28]$, but no homologues to these proteins were detected in most other malaria pathogens. Therefore, it is conceivable that the PIR proteins, which are also expressed on the surface membrane of pRBCs, are as well involved in adherence to endothelial cells and sequestration of pRBCs in the microvasculature of inner organs.

The complex phenomenon of sequestration is hitherto not completely understood as indicated by the common assumption that sequestration of mature pRBCs in the microvasculature of the host tissues, as found in $P$. falciparum infections, does not occur for $P$. vivax. Thus, it has been assumed that the human parasite $P$. vivax must have developed different strategies e.g. adherence to barrier cells in the spleen to avoid spleen clearance [29]. Recently, however, in vitro assays provided new evidence for a cytoadherence of $P$. vivax pRBCs to endothelial cells and placental cryosections suggesting a cytoadherence comparable to that of $P$. falciparum pRBCs in vivo [30]. Direct or indirect evidences for an involvement of VIR antigens in binding to host receptors are currently still missing. In the most studied rodent model $P$. berghei, real-time in vivo imaging of transgenic parasites revealed CD36-mediated sequestration of schizonts in adipose tissues and lung as well as an accumulation of schizonts in the spleen [31]. Accumulation of other blood stages was also observed in different tissues including the brain and placenta of pregnant mice [32-34]. Nevertheless, identification of parasite ligands involved in binding to CD36 or other host receptors are still missing. In vitro adherence of $P$. chabaudi infected erythrocytes to purified human CD36 has been observed [35]. Moreover, sequestration to microvascular endothelial cells was reported to appear in an organ specific manner in P. chabaudi infections, predominantly in liver, but also in brain and spleen thus resembling at least partially the sequestration pattern in P. falciparum infections.

In this study, the relationship between antigenic variation of the cir multigene family and accumulation of parasites localization in different host tissues was analysed at the molecular level. Bioinformatic characterization of the cir genes was used to identify different subfamilies within the multigene family. First indications for a tissue-specific expression of cir genes were 
obtained by amplification of a representative sample of transcribed cir genes from different host tissues. Transcriptional profiling analyses of cir genes in different host tissues using RFLP analysis of RT-PCR products provided further evidence of a tissue-specific expression of cir genes in P. chabaudi infections. These results provide first indications for a possible correlation of antigenic variation of the cir multigene family and sequestration in host tissues in $P$. chabaudi infections.

\section{Methods}

\section{Bioinformatics}

All annotated sequence data of putative cir genes in the Plasmodium Genome Database Resource version 8.0 [36] (PlasmoDB; plasmodb.org) were compiled (Additional file 1). For confirmation of correct annotation, a CD-BLAST [37-39] was performed to identify and locate the conserved domain of the CIR-BIR-YIR superfamily $[22,23]$ (Pfam protein families database accession number [PF06022]). Sequences with a partial CIR-BIR-YIR conserved domain were excluded from all subsequent analyses.

For phylogenetic reconstruction, putative CIR proteins were aligned using ClustalW2 [40] and a phylogenetic tree was calculated with PhyML 3.0 [41] using maximum likelihood estimation and the JTT model [42] for amino acid substitution. The gamma shape parameter and the proportion of invariable sites were estimated and the number of substitution rate categories was set to four. The implemented BIONJ algorithm was used to build the starting tree. Resulting trees (Newick format) were visualised and processed with MEGA4 [43,44].

For validation of structural protein motifs such as transmembrane domains, signal peptides and PEXEL motifs, analyses of the protein sequences were examined with Protscale [45], TMHMM $2.0[46,47]$ and SignalP [48]. Results were compared with annotations extracted from PlasmoDB.

\section{Mice}

All experiments were performed with 5-8 weeks-old outbred female NMRI mice (Crl:NMRI(Han)) provided by Charles River (Sulzfeld, Germany). The mice were kept in cages with a maximum of five animals per cage and received food and water ad libitum. The experiments were planed according to all relevant guidelines for animal protection and approved by German authorities responsible for animal protection.

\section{Infection of mice}

A non-clonal line of $P$. chabaudi very similar but not identical to $P$. chabaudi AS was used [49-51]. Blood stages of $P$. chabaudi were weekly passaged in female NMRI mice by intraperitoneal injection (i.p.) of a droplet of tail vein blood diluted in PBS. Parasitaemia was evaluated in Giemsa-stained blood smears and total erythrocytes number was counted in a Neubauer chamber.

For the experiments, blood of an infected NMRI mouse was collected by cardiac puncture under anesthesia. For each transcriptional profiling experiment, six mice were infected i.p. with approximately 100 parasitized red blood cells (pRBCs). Organs and blood were collected at about $30 \%$ parasitaemia, i.e. just before peak parasitaemia.

For transcriptional profiling during the course of an infection, tail vein blood of mice infected i.p. with 100 pRBCs was passaged i.p. into naïve female NMRI mice at days 7 (early infection), 14 (around peak parasitaemia), 21 (7 days after peak parasitaemia) and 35 (21 days after peak parasitaemia). Expression of cir genes was analysed when parasitaemia reached about $30 \%$.

\section{RNA and DNA extraction}

Blood samples of P. chabaudi infected mice were collected by cardiac puncture, rapidly frozen and stored at $-80^{\circ} \mathrm{C}$. Small pieces of liver, spleen, kidneys, lung and brain were transferred into RNA Later (Sigma Aldrich) and kept at $-80^{\circ} \mathrm{C}$ for long-term storage. Total RNA was extracted using NucleoSpin ${ }^{\circledR}$ RNA II kit (MachereyNagel) according to the manufactures instructions. Genomic DNA extraction was performed with the NucleoSpin ${ }^{\circledR}$ Blood kit (Macherey-Nagel).

\section{Verification of complete cir gene structures}

To verify the complete gene structure of selected cir genes, RT-PCR and genomic PCR were performed in parallel. The primer pairs used for amplification and detailed information about PCR conditions can be found in Additional file 2.

\section{Cloning of RT-PCR products and sequencing}

Residual contaminating genomic DNA in total RNA preparations was digested with DNase I (Fermentas). First strand cDNA was synthesised using $1 \mu \mathrm{g}$ RNA and the RevertAid ${ }^{\mathrm{TM}}$ Premium Reverse Transcriptase (Fermentas) with Oligo $\mathrm{dT}_{18}$ primers including reactions without reverse transcriptase as negative controls for amplification.

For transcription analysis, specific primers spanning the second exon encoding an essential part of the CIRBIR-YIR domain (> 98\% of its length) were designed for both major cir gene subfamilies. The primer pairs f1up (5'-AATACGCTATTTTATGGTTTAGTTATAAA-3')/ f1lo (5' - TGAAATTCCTAAAATAATGGGTATTATTAAAA-3') and f2up (5'-TATGCTATTTTATGGTTAAGTTATATGCTA-3')/f2lo (5'-ATGAATACTTA TAAGCAATTCCCAAGAAAA-3') were targeted to 
highly conserved sequence regions for amplification of a broad range of cir genes.

Following cDNA synthesis, amplification with the AccuPrime $^{\mathrm{TM}}$ DNA polymerase (Invitrogen) was performed using subfamily-specific primers for cir subfamily 1 and 2. After an initial denaturation for $30 \mathrm{~s}$ at $94^{\circ}$ C, 40 cycles of $10 \mathrm{~s}$ at $94^{\circ} \mathrm{C}, 30 \mathrm{~s}$ at $55^{\circ} \mathrm{C}, 30 \mathrm{~s}$ at $72^{\circ} \mathrm{C}$ followed by a final extension of $10 \mathrm{~min}$ at $72^{\circ} \mathrm{C}$. RTPCR products were then isolated from a $0.8 \%$ agarose gel and precipitated in the presence of glycogen.

In order to sample a first repertoire of transcribed $P$. chabaudi cir genes, RT-PCR products of each tissue (blood, liver, spleen, kidney, lung and brain) were gelpurified and cloned into the $\mathrm{pCR}^{\mathrm{TM}} 4-\mathrm{TOPO}^{\circledR}$ TA vector (Invitrogen). Thirty-six clones for each tissue and subfamily were sequenced (GATC, Constance, Germany) resulting in sequences for 216 independent cDNA clones for cir subfamily 1 and 2.

\section{Transcriptional profiling of RT-PCR products by RFLP}

For transcriptional profiling, DNase digestion of RNA and cDNA synthesis was performed as described before and RT-PCR products were amplified with the Phusion ${ }^{\circledR}$ Hot Start II High-Fidelity DNA Polymerase (Fermentas) using subfamily-specific primers for cir subfamily 1 and 2. After an initial denaturation for $30 \mathrm{~s}$ at $98^{\circ} \mathrm{C}, 50$ cycles of $10 \mathrm{~s}$ at $98^{\circ} \mathrm{C}, 30 \mathrm{~s}$ at $55^{\circ} \mathrm{C}, 30 \mathrm{~s}$ at $72^{\circ} \mathrm{C}$ were performed followed by a final extension for $10 \mathrm{~min}$ at $72^{\circ} \mathrm{C}$.

Gel-purified RT-PCR products (150 ng) were digested with AluI or XapI (Fermentas) in $5 \mu \mathrm{l}$ for $3 \mathrm{~h}$ at $37^{\circ} \mathrm{C}$ followed by enzyme inactivation for $20 \mathrm{~min}$ at $65^{\circ} \mathrm{C}$. The restricted fragments (30 ng) were analysed with the Agilent 2100 Bioanalyzer using the DNA 1000 LabChip $^{\circledR}$ kit (Agilent) following the manufactures instructions. In order to ensure reproducibility of the RFLP profiles, both RT-PCR and RFPL were usually repeated at least twice resulting in 4 replicates.

\section{Statistical analyses}

In order to evaluate whether clones representing certain cir subfamilies were significantly more frequently recovered from one tissue than from others, frequencies were compared using a Z-test.

\section{Results \\ Phylogenetic analyses of putative CIR proteins in PlasmoDB}

A total of 199 putative CIR proteins had been annotated in the Plasmodium Genome Database Resource (state September 2011) as cir genes. For confirmation of correct annotation, the putative CIR sequences were examined regarding the conserved domain of the CIR-BIRYIR Superfamily (accession number [PF06022] for the
Pfam database). This conserved sequence motif were found in several CIR, BIR and YIR proteins of the Plasmodium species $P$. chabaudi, $P$. berghei and $P$. yoelii (Figure 1) [22,23]. The presence of a complete conserved domain of the CIR-BIR-YIR superfamily could only be confirmed for 186 of them. For the remaining 13 putative CIR proteins, no (four sequences) or only a partial CIR-BIR-YIR conserved domain (seven sequences) could be identified. As there was no evidence for the missing regions in the adjacent genomic sequences, these database entries most like represent cir pseudogene fragments. These sequences were excluded from all subsequent analyses. Furthermore, three sequences (PCHAS_040020; PCHAS_000130; PCHAS_000400) showed two hits for the CIR-BIR-YIR conserved domain. In these cases the first hit only represented a partial domain and these partial domains were therefore also excluded. The final 186 putative CIR proteins containing a complete conserved CIR-BIR-YIR domain were used for all following analyses and are listed in Additional File 1. Due to the fact that the $P$. chabaudi genome is assembled already to 14 (more or less) complete chromosomes whereas the $P$. yoelii genomic sequence is still scattered on 5.617 unassembled contigs, it is highly probable that vast majority of the cir genes in the genome have been identified and annotated in the current PlasmoDB release (8.0) and that the number of cir genes is indeed much smaller than the number of yir genes (about 838 genes) [52].

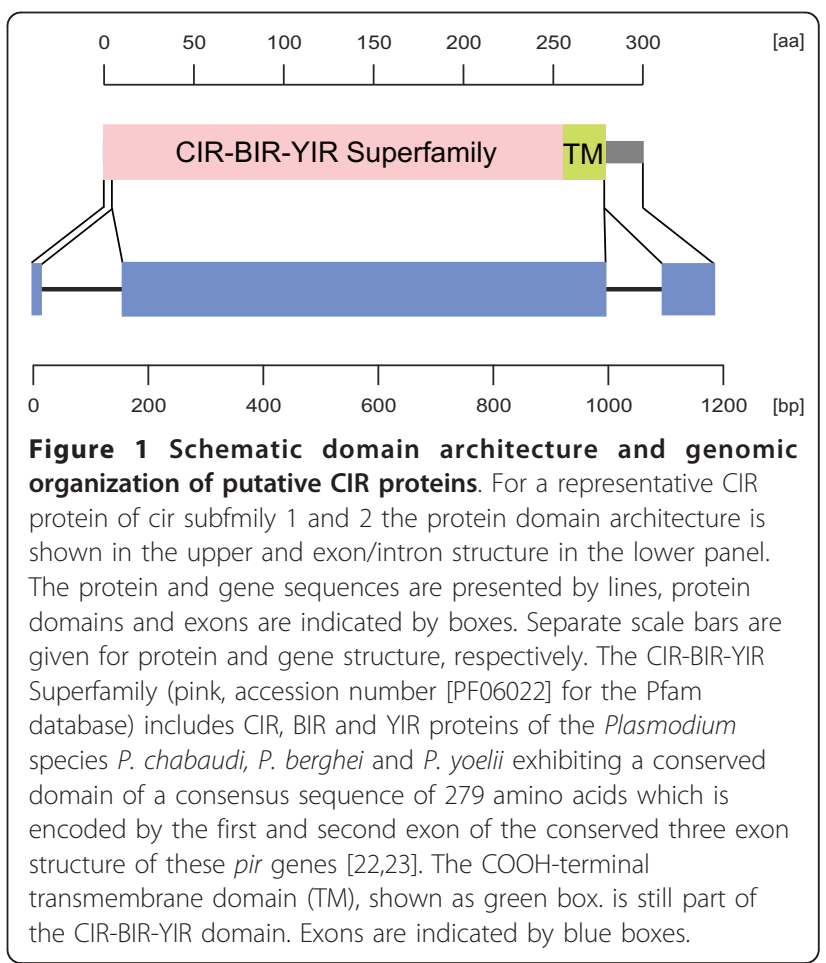


The phylogenetic maximum likelihood analysis of all 186 annotated CIR domains including a selected subset of the related YIR proteins in P. yoelii using representatives of all different subgroups defined previously in the yir family [52] (Figure 2) identified four distinct branches. Three large branches of CIR proteins were indicated with likelihood ratios of more than $95 \%$ as statistical support values at the nodes and one small branch with $92 \%$ support. Two of these branches were designated here as subfamily 1 and 2 containing CIR amino acid sequences that show a relatively low variability within the subfamilies and are very similar to well known YIR and BIR proteins in terms of size and overall structure. The other two branches with more divergent CIR proteins were not designated as a specific subfamily due to their high heterogeneity. In contrast to subfamily 1 and 2, these unassigned branches include many very long CIRs. In most cases these proteins exhibit an additional highly variable insertion within the CIR-BIR-YIR domain. Such divergent family members have already been described in previous studies of the PIRs superfamily [20]. Interestingly, the analysis also reveals important information about the relationship between CIR and YIR proteins. The phylogenetic tree indicated that the

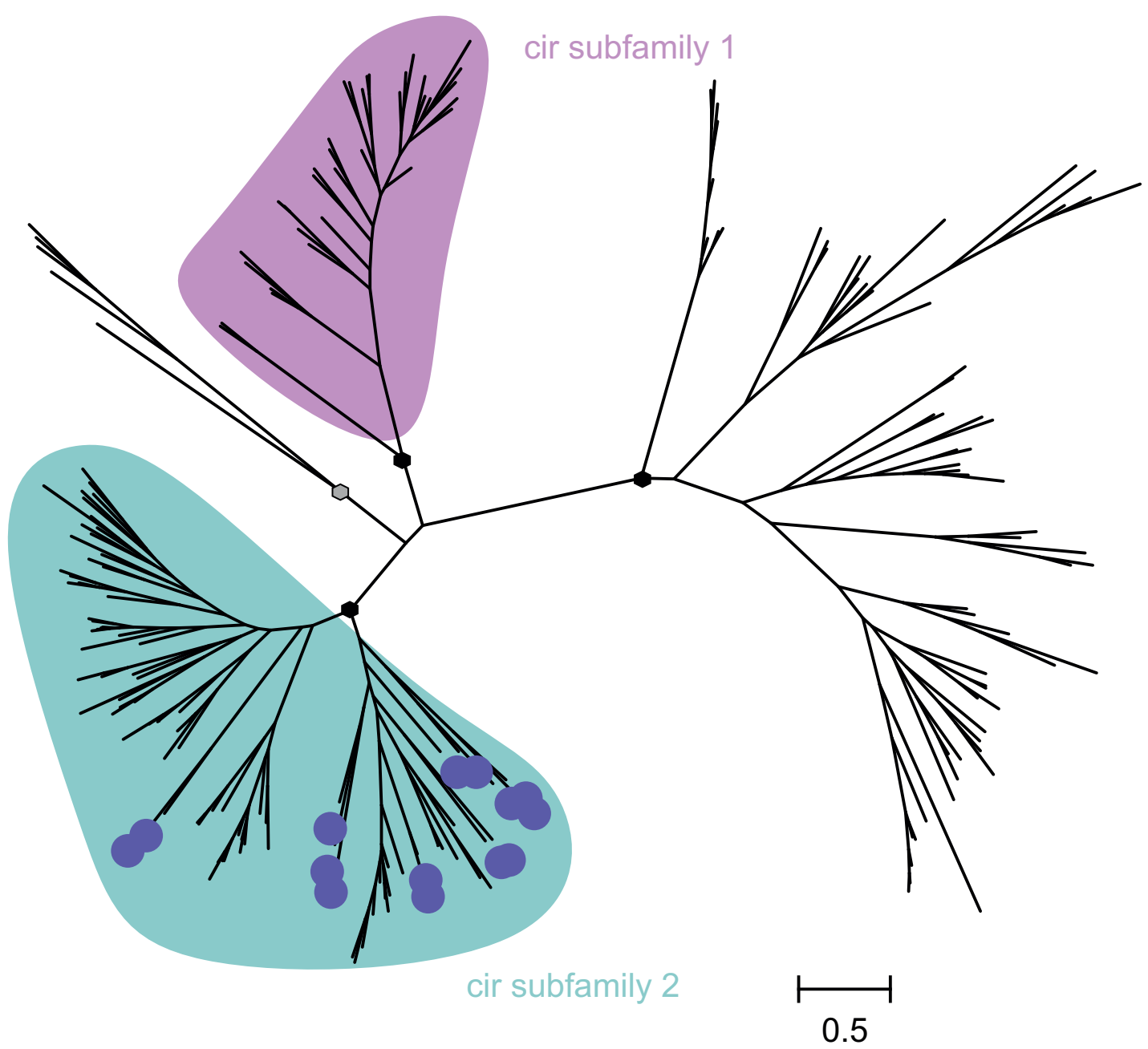

Figure 2 Phylogenetic tree of 186 annotated CIR and selected YIR proteins. Sequences of 186 CIR-BIR-YIR conserved domains of the putative CIR proteins and 14 different putative conserved domains of YIRs representing different YIR subfamily proteins were aligned using ClustalW2 [40] and a maximum likelihood tree was calculated using PhyML [41]. The cir subfamilies, indicated by the unrooted phylogenetic tree, are highlighted by different colours. Subfamily 1 (purple) and subfamily 2 (cyan) consist of CIR proteins very similar to well known YIR and BIR proteins of the PIR superfamily [20]. The remaining CIR proteins were more divergent, often due to highly variable insertions within the CIR-BIRYIR conserved domain. These sequences were finally not assigned to any subfamily. The phylogenetic tree indicated that the YIR proteins cluster only with subfamily 2 and neither with subfamily 1 nor the large CIR proteins. The putative YIR domains are indicated by blue circles. The scale bar represents 0.5 substitutions per amino acid position. Black hexagons mark major branches with more than 95\% support, the grey hexagon labels the minor branch with 92\% support. See in Additional file 3 for identification of the individual proteins in each branch. 
subset of YIR proteins shares similarities only with the predicted subfamily 2 but neither with subfamily 1 nor the unassigned heterogeneous CIR sequences.

For identification of the individual proteins in each branch, the phylogenetic tree of CIR and YIR proteins is given in Newick format in Additional file 3.

\section{Localization motifs found in CIR proteins}

For protein structural analyses, the 186 putative CIR proteins were examined in regard to subcellular localization characteristics, such as putative signal peptides, transmembrane domains, and the PEXEL motif (Plasmodium export element) [53,54]. Results were then compared to annotations in PlasmoDB. Detailed information on protein motifs identified in all putative CIR proteins can be obtained from Additional file 1. In only one of the 186 sequences (PCHAS_114740) a signal peptide had been annotated, however, the re-analysis with SignalP revealed only a $1.6 \%$ probability for the presence of a signal peptide in this particular predicted CIR protein with a maximum cleavage site probability of $1.2 \%$ between amino acid position 26 and 27. Moreover, a cDNA sequence encoding a corresponding CIR protein with signal peptide could not be amplified by RT-PCR using primers derived from PCHAS_114740 in the nonclonal $P$. chabaudi line used throughout this study. Altogether, this indicates that the CIR proteins lack a signal peptide and presumably use alternative pathways for transport out of the parasite cell across the parasitophorous vacuole to the host cell membrane.

For the vast majority of putative CIR proteins (147 sequences) the presence of one transmembrane domain had been annotated in PlasmoDB. Hydrophobicity plot analyses according to Kyte and Doolittle were performed using Protscale [45] confirming a hydrophobic stretch close to the $\mathrm{COOH}$-terminus of these CIRs. A prediction of transmembrane topology using TMHMM 2.0 [47] indicated a transmembrane helix of approximately 23 amino acid residues immediately upstream of the $\mathrm{COOH}$-terminus of the CIR-BIR-YIR conserved domain with a probability of more than $99 \%$. The largest part of the $\mathrm{NH}_{2}$-terminus of CIR proteins was predicted to be located outside and only less than 30 amino acids inside the cytoplasm. The corresponding hydrophobicity plots as well as the predicted transmembrane topology for representative CIR proteins of subfamily 1 and 2 are shown in Figure 3A and 3B. For a notably lower proportion of CIR proteins (37 sequences) two transmembrane helices and for one CIR sequence (PCHAS_011490) even three transmembrane helices had been annotated. The phylogenetic analysis revealed that all these protein sequences were unassigned CIRs and did not belong to subfamily 1 or 2 . The hydrophobicity analyses indicated an additional second hydrophobic stretch behind the
CIR-BIR-YIR conserved domain immediately at the $\mathrm{COOH}$-terminus in these CIRs. The predicted transmembrane topology by TMHMM also suggested the presence of two transmembrane helices, both spanning the membrane with 23 amino acids. In this case not only the large $\mathrm{NH}_{2}$-terminal CIR domain but also a segment of less than 10 amino acids at the $\mathrm{COOH}$-terminus were predicted to be outside (Figure 3C). For the putative sequence PCHAS_011490 with three predicted transmembrane domains, two additional helices were found behind the CIR-BIR-YIR conserved domain by Protscale. The schematic transmembrane topology for selected CIR proteins is given in Figure 3D and 3E.

Finally, the putative CIR proteins were scanned for the conserved five-residue PEXEL motif $\operatorname{Rx}[\mathrm{L} / \mathrm{I}] \mathrm{x}[\mathrm{E} / \mathrm{Q} / \mathrm{D}]$ with the Protein Motif Pattern search tool in PlasmoDB. This short hydrophobic peptide has been proposed to be localised 16-24 amino acids downstream of the $\mathrm{NH}_{2-}$ terminus and to mediate the export of proteins across the parasitophorous vacuole to the erythrocyte cytoplasm [53,54]. Seventeen sequences of the putative CIR proteins were identified to have the specific PEXEL motif but none of these sequences exhibited the PEXEL motif at its canonical position. In the protein sequence PCHAS_114700 the motif is located at amino acid position 4-8 and in four sequences between position 30-70. In another 10 small CIR proteins and in two large CIR proteins, the PEXEL motif is found between the amino acids $90-300$ or $640-660$, much closer to the $\mathrm{COOH}$ than to the $\mathrm{NH}_{2}$-terminus. Hence, all annotated putative CIR proteins only possess an $\operatorname{Rx}[\mathrm{L} / \mathrm{I}] \mathrm{x}[\mathrm{E} / \mathrm{Q} / \mathrm{D}]$ stretch in their sequence but lack a functioning PEXEL motif.

\section{Verification of complete gene structures}

In several studies, a common three-exon gene structure was postulated for genes of the pir superfamily in rodent malaria parasites $[15,23,24]$. For verification of the complete gene structure of selected cir genes of subfamily 1 and 2, further bioinformatic analyses and experimental tests such as parallel RT- and genomic PCR were performed. The results show that indeed the cir genes consists of three exons like the related yir genes of $P$. yoelii $[25,52]$. The coding region of cir cDNAs is unevenly distributed between these exons with about $15 \mathrm{bp}$ of the open reading frame in the first, 800-840 bp (highly polymorphic but containing highly conserved motifs) in the second, and 80-90 bp in the third exon. The two introns of 100-150 bp are found in conserved positions (Figure 4). Moreover, evidence for the occurrence of minor splice variants of cir genes was detected by comparison of RT-PCR and genomic PCR products. Transcripts of cir genes were amplified where alternative splicing of the first exon was detected leading to an $\mathrm{NH}_{2}$-terminally truncated putative protein. In this case a 'cryptic' 5 ' 


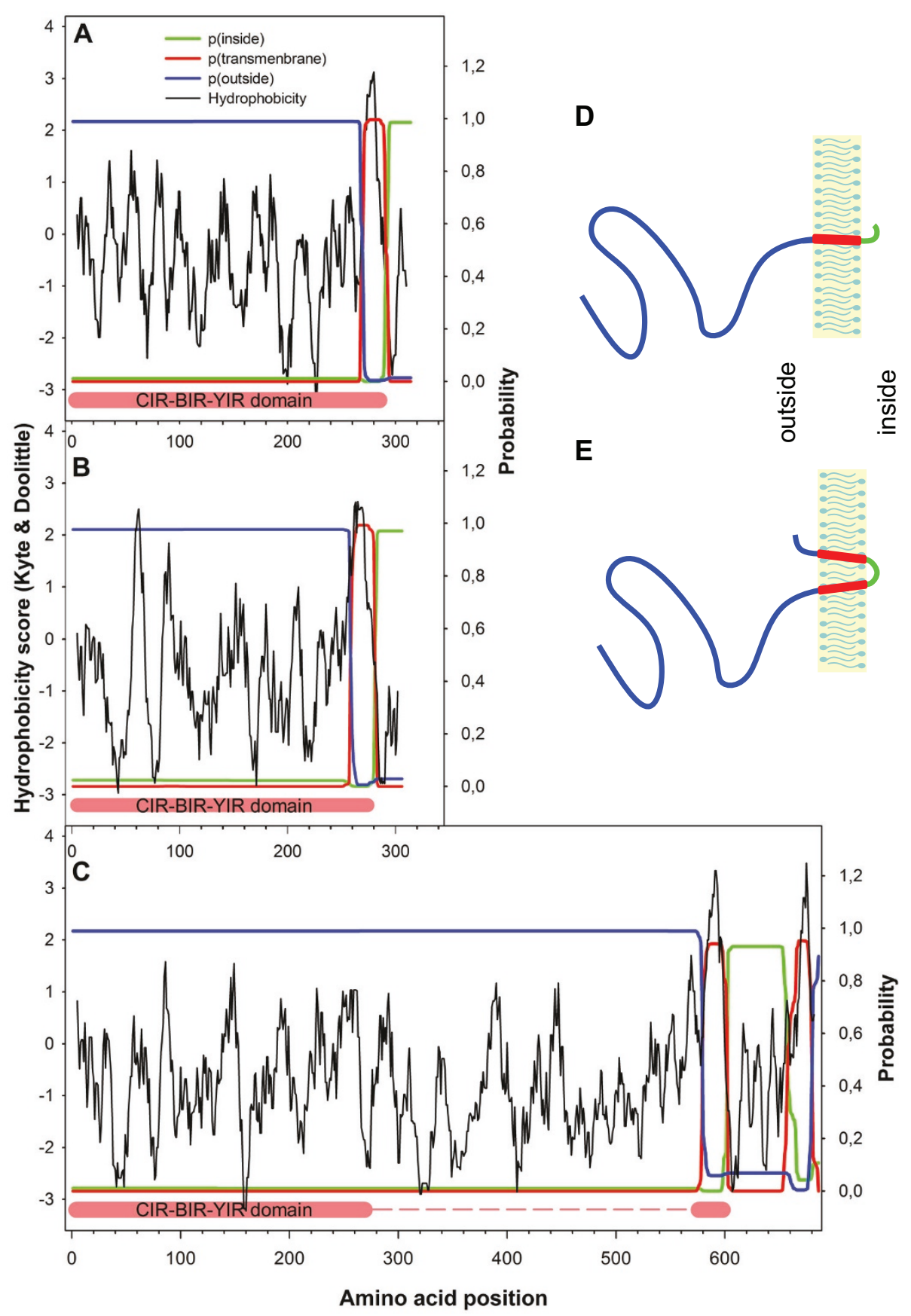

Figure 3 Transmembrane topology of some selected CIR proteins. To examine the predicted transmembrane topology of selected CIR Proteins two different analyses tools were used. With the Protscale analysis, hydrophobicity plots were created according Kyte \& Doolite [45]. With the TMHMMM 2.0 server [47], probabilities of predicted transmembrane topologies were calculated. For three different CIR proteins (A-C) the results of the Protscale and TMHMM 2.0 were here compiled in one graph. On the $x$-axis the amino acid positions are given whereas on the left $y$-axis the hydrophobicity scores and on the right $y$-axes the probabilities for extracellular, intracellular and transmembrane localization are shown, respectively. The CIR proteins PCHAS_060060 of subfamily 1 (A) and PCHAS_000320 of subfamily 2 (B) were analysed as well as one of the unassigned CIR protein (PCHAS_010040) (C). For the first two proteins, only one transmembrane helix was predicted with more than 99\% probability immediately close to the $\mathrm{COOH}$-terminus of the $\mathrm{CIR}$-BIR-YIR conserved domain, whereas the long $\mathrm{NH}_{2}$-termininal part was assumed to be located outside. For the longer unassigned CIR protein, an additional second helix was located behind the CIR-BIR-YIR conserved domain close to the $\mathrm{COOH}$-terminus in this $\mathrm{CIR}$. The large $\mathrm{NH}_{2}$-terminus as well as less than 10 amino acids of the $\mathrm{COOH}$-terminus were predicted to be outside. The individual curves were highlighted by different colours (see graphic legend). Additionally, schematic presentations of the transmembrane topologies of subfamily 1 and 2 CIR proteins are schematically shown in (D) while topology of a CIR protein with two predicted transmembrane helices is given in (E). 
splice-site within the non-coding region of the first exon was used whereas the 3' splice-site was identical in both transcripts (Additional file 4). Whether this splice variant encodes a functionally important CIR protein variant or represents only a mis-spliced product can not finally be decided from the available data. Sequences of genomic DNA and full-length cDNA sequences have been deposited in GenBank with accession numbers [GenBank:JF904729 - JF904735] (Additional file 2).

\section{RT-PCR of cir genes with subfamily-specific primers}

For the subsequent transcriptional profiling analyses (see below), subfamily-specific primers for cir subfamily 1 and subfamily 2 were designed spanning the second exon, the essential part of the CIR-BIR-YIR conserved domain. The primer pairs were located at highly conserved sequence regions for amplification of a broad range of cir cDNAs (Figure 4A). The expected RT-PCR

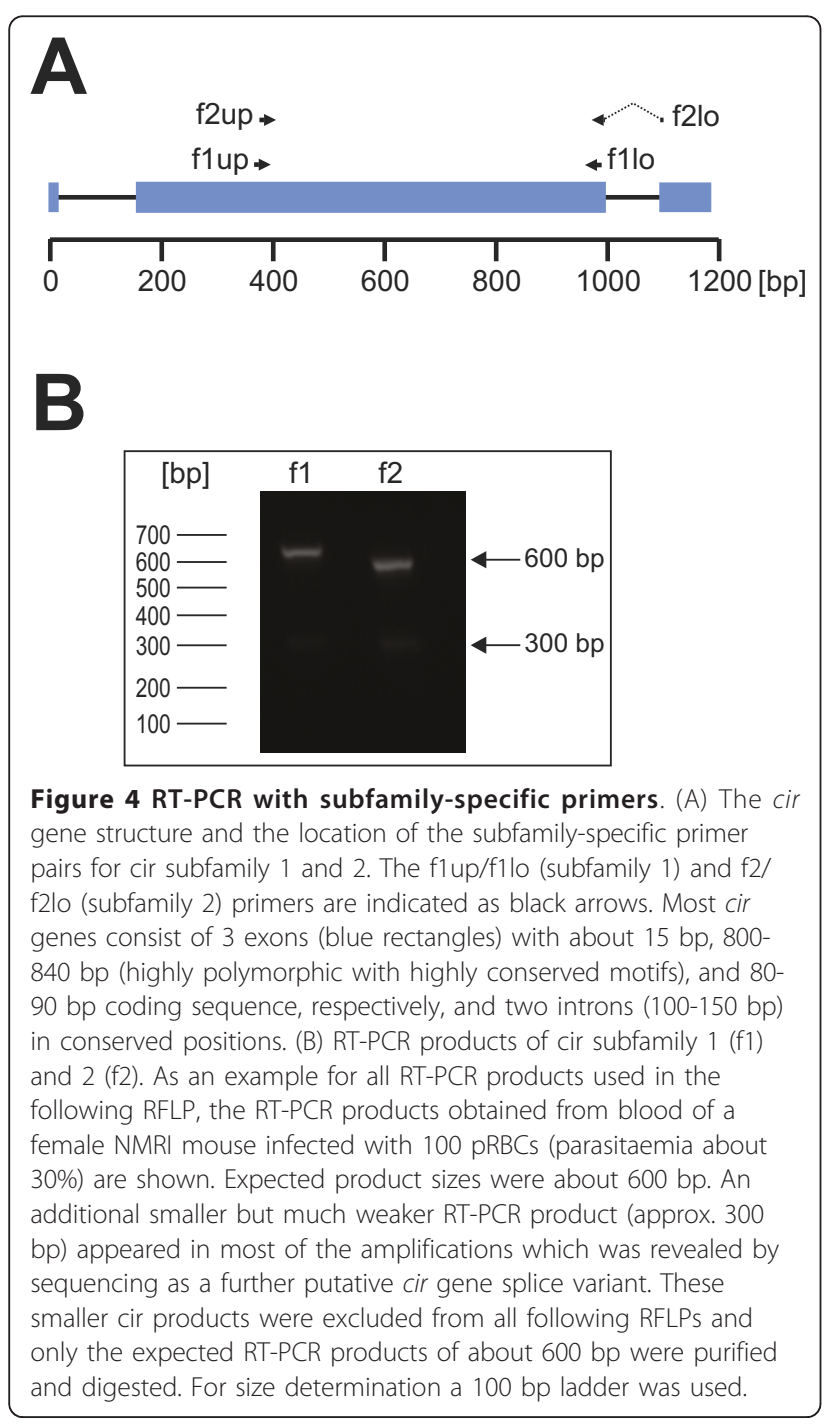

product sizes for subfamily 1 and subfamily 2 were about 600 bp (Figure 4B). In most PCRs, however, an additional smaller but very faint RT-PCR product (approx. $300 \mathrm{bp}$ ) appeared. Sequencing analyses indicated that this product is a notably smaller cir transcript with a deletion of about $250 \mathrm{bp}$ within the second exon. This cDNA most likely also represents an alternatively spliced cir variant, in particular since this cDNA [GenBank:JF969288] has an uninterrupted open reading frame.

\section{Cloning of cir cDNAs from individual tissues}

To examine whether the expression of certain cir antigen mRNAs correlates with the localization of the parasites in particular internal organs, a first repertoire of transcribed cir genes was amplified from parasites using RT-PCR and subfamily-specific primers for subfamilies 1 and 2. For this purpose, a single female NMRI mouse was i.p. infected with $100 \mathrm{pRBCs}$ and, at a parasitaemia of $30 \%$, blood, liver, spleen, kidney, lung and brain were collected for RNA isolation. RT-PCR products of about $600 \mathrm{bp}$ from each tissue were excised from agarose gels and directly cloned into the pCR4-TOPO vector. For each tissue, clones were obtained from at least three independent RT-PCR reactions. Thirty-six clones for each tissue and subfamily were sequenced resulting in 216 cir sequences for each cir subfamily. Information about individual sequences with GenBank ${ }^{\circledR}$ accession numbers can be found in Additional file 5. A broad range of different sequences from both subfamilies was amplified as shown by phylogenetic maximum likelihood analysis of the deduced protein sequences in comparison with the 186 putative conserved domains obtained from PlasmoDB (Additional file 6) indicating that the method is able to amplify a representative repertoire of both subfamilies. The facts that (i) the length of the amplified fragments differs only minimally (mean length and SD is $561 \mathrm{bp} \pm 2.5 \%$ for subfamily 1 and $523.7 \mathrm{bp} \pm 4.4 \%$ for subfamily 2) and (ii) the percent identity is very high (mean percent identity and SD is $80.8 \% \pm 8.5 \%$ for subfamily 1 and $76.7 \% \pm 10.9 \%$ for subfamily 2 ) a strong bias introduced by unequal amplification efficacies is at least unlikely.

The phylogenetic analyses of the proteins deduced from subfamily 1 cir cDNA sequences identified nine different sequence subgroups within the repertoire of expressed subfamily 1 cir genes. Branch lengths and likelihood ratios for nodes with at least $90 \%$ support indicated that the transcribed cir sequences within these subgroups are very similar or even identical (Figure 5). See in Additional file 7 for the Newick format of the phylogenetic tree of cir subfamily 1 .

Statistical analyses using a Z-test were done to identify significant differences in the frequency of different 


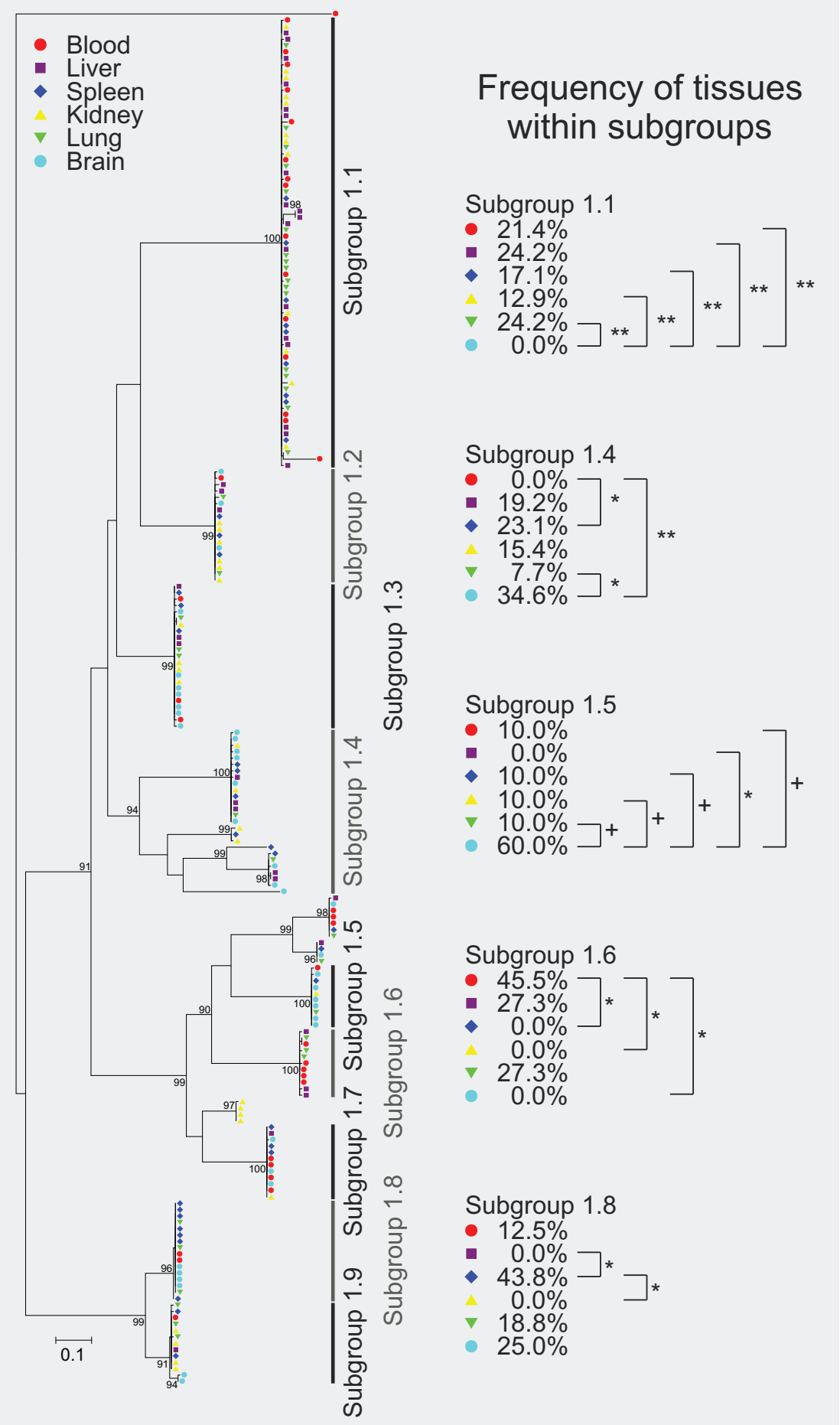

Figure 5 Phylogenetic tree representing frequency of tissues within subgroups of the cir subfamily 1 . Deduced protein sequences from 216 amplified cir cDNAs of subfamily 1 amplified from six different host tissues of a single female NMRI mouse infected with 100 pRBCs (parasitaemia about 30\%) were aligned using ClustalW2 [40] and a maximum likelihood tree was calculated using PhyML [41]. RT-PCR products for each tissue (blood, liver, spleen, kidney, lung and brain) were cloned and 36 clones from each tissue were sequenced. Statistical support is indicated as likelihood ratios only for those nodes with at least $90 \%$ support. The scale bar represents 0.1 substitutions per amino acid position. The origins of sequences (host tissues) are indicated by different colours as shown in the figure graphic legend. The cir subfamily 1 repertoire expressed here can be divided in 9 subgroups. Five of these subgroups (subgroup 1.1, 1.4, 1.5, 1.6, 1.8) showed significant differences in frequency of tissues. The $p$-values were calculated by Z-test; ${ }^{* *} p<0.01 ;{ }^{*} p<0.05 ;{ }^{+} p<0.07$ ). Small (rarely occurring) subgroups of cir cDNAs were excluded from the statistical analysis. For identification of the individual sequences in each branch see Additional file 7. 
tissues represented within those individual subfamilies that are sufficiently represented within the total population. The method does not allow to detect expression differences for minor cir transcripts. Results are also indicated in Figure 5. Most remarkably, the cir cDNA belonging to subgroup 1.1 could be frequently recovered from liver (24.2\% of all subgroup 1.1 clones), lung, (24.2\%) blood (21.4\%), spleen (17.1\%) and kidney (12.9\%) but not from brain (0\%). The absence of this cir cDNA from our brain samples is statistically significant when compared to all other tissues $(\mathrm{p}<0.01)$. In contrast, the cir cDNA sequences of subgroup 1.4 were not found in blood cDNA but significantly more often present in brain $(34.6 \%$; p < 0.01) and spleen $(23.1 \%$; p < $0.05)$ samples. Furthermore, a significant difference could be detected between brain and lung (7.7\%) in subgroup 1.4 ( $\mathrm{p}<0.05)$. The cir cDNAs in subgroup 1.5 were absent from liver samples $(0 \%)$ but a higher number $(60 \%)$ of these clones came from brain samples than from all other tissues investigated (10\% for each tissue). While the differences between brain and liver were statistically significant $(\mathrm{p}<0.05)$, differences between brain and the other tissues (10\%) did just not reach significance $(\mathrm{p}<0.07)$. The cDNA sequences of subgroup 1.6 were absent from spleen, kidney and brain samples but were found in blood (45.5\%), liver $(27.3 \%)$ and lung (27.3\%). The frequency of clones obtained from blood within the cir subgroup 1.6 were significantly higher when compared to spleen, kidney and brain $(\mathrm{p}<0.01)$. Finally, for subgroup 1.8 no cir cDNAs could be detected in liver and kidney. In contrast, this subgroup was obtained with a high frequency of $43.8 \%$ from the spleen and with intermediate frequencies of $12.5 \%$ from blood, 18.8\% from lung and 25.0\% from brain. However, only the differences between the frequencies for spleen, liver and kidney were statistically significant $(\mathrm{p}<0.05)$.

An equivalent analysis was done for the cir subfamily 2 (Figure 6). However, only minor differences in tissue distribution of cir cDNAs could be found within the 7 subgroups identified in the expressed set of subfamily 2 cir genes. Significant differences in the frequency between tissues were shown only in three subgroups of cir subfamily 2 . In subgroup 2.5 , a significant difference was observed only between blood with a frequency of $30.2 \%$ and brain with a frequency of $7.6 \%(\mathrm{p}<0.01)$. Differences between blood and liver (13.2\%) as well as blood and kidney (9.4\%) did just not reach significance $(\mathrm{p}<0.07)$. In subgroup 2.6, the absence of cDNAs obtained from brain resulted in a statistical difference only to the frequency of clones derived from liver and spleen samples with frequencies of $35.0 \%$ and $30 \%$, respectively $(\mathrm{p}<0.05)$. Within the cir cDNA sequences in subgroup 2.7, frequency of clones recovered from brain was significantly increased in brain (25\%) compared to all other tissues with $\mathrm{p}<0.01$ for blood (7.7\%) and $\mathrm{p}<0.05$ for liver (11.5\%), spleen (11.5\%), kidney (11.5\%), and lung (11.5\%). See in Additional file 8 for the Newick format of the phylogenetic tree of cir subfamily 2 .

All these differences in tissue distribution of the transcribed cir cDNAs found in this cloning and sequencing study are first indications for a tissues specific expression of cir genes and were analysed in more detail in the subsequent experiments.

\section{Expression profiling of cir genes in different host tissues}

Due to these first differences in the expression of cir genes, further analyses of different transcription profiles in various host tissues during the infection were carried out using RFLP of RT-PCR products in order to confirm differences in expression of cir genes between different host tissues for a larger number of mice.

Therefore, six mice were infected i.p. with 100 pRBCs. Only four out of these six mice developed a patent infection indicating that $100 \mathrm{pRBCs}$ i.p. is close to the minimal infectious dose and that the initial diversity of parasites is kept at a minimum using this infection protocol. Organs and blood were again collected at about $30 \%$ parasitaemia, i.e. just before peak parasitaemia. After amplification using the subfamily 1 and subfamily 2 specific primers, PCR products were digested with the restriction enzyme $A l u \mathrm{I}$ and analysed using the DNA 1000 kit for the Agilent 2100 bioanalyzer for accurate and reproducible separation and size determination (Figure 7).

Comparing the RFLP profiles, considerable differences in the banding patterns of the individual organs for subfamily 1 and 2 were observed thus confirming differences in expression of cir mRNAs between different host tissues. Nevertheless, the prominent fragments observed in RFLP agreed in many, though not all cases well with the restriction pattern obtained in silico from the sequences of the cir clones described above (see Additional file 9). This similarity of experimental RFLP patterns and the in silico predicted restriction patterns of some cir cDNA sequences of the cloning and sequencing experiment suggested at least a similar repertoire of amplified cir genes in both infection experiments. On the other hand, none of the profile pattern was identical between the four mice infected with 100 P. chabaudi pRBCs taken from the same parental population. This indicates that random selection of $100 \mathrm{pRBCs}$ as starter population from a large parental population severely influences the initial cir gene expression pattern. Despite the fact that patterns for organs differed within individual mice, there was no clear tissue-specific pattern detectable that was conserved between mice. 


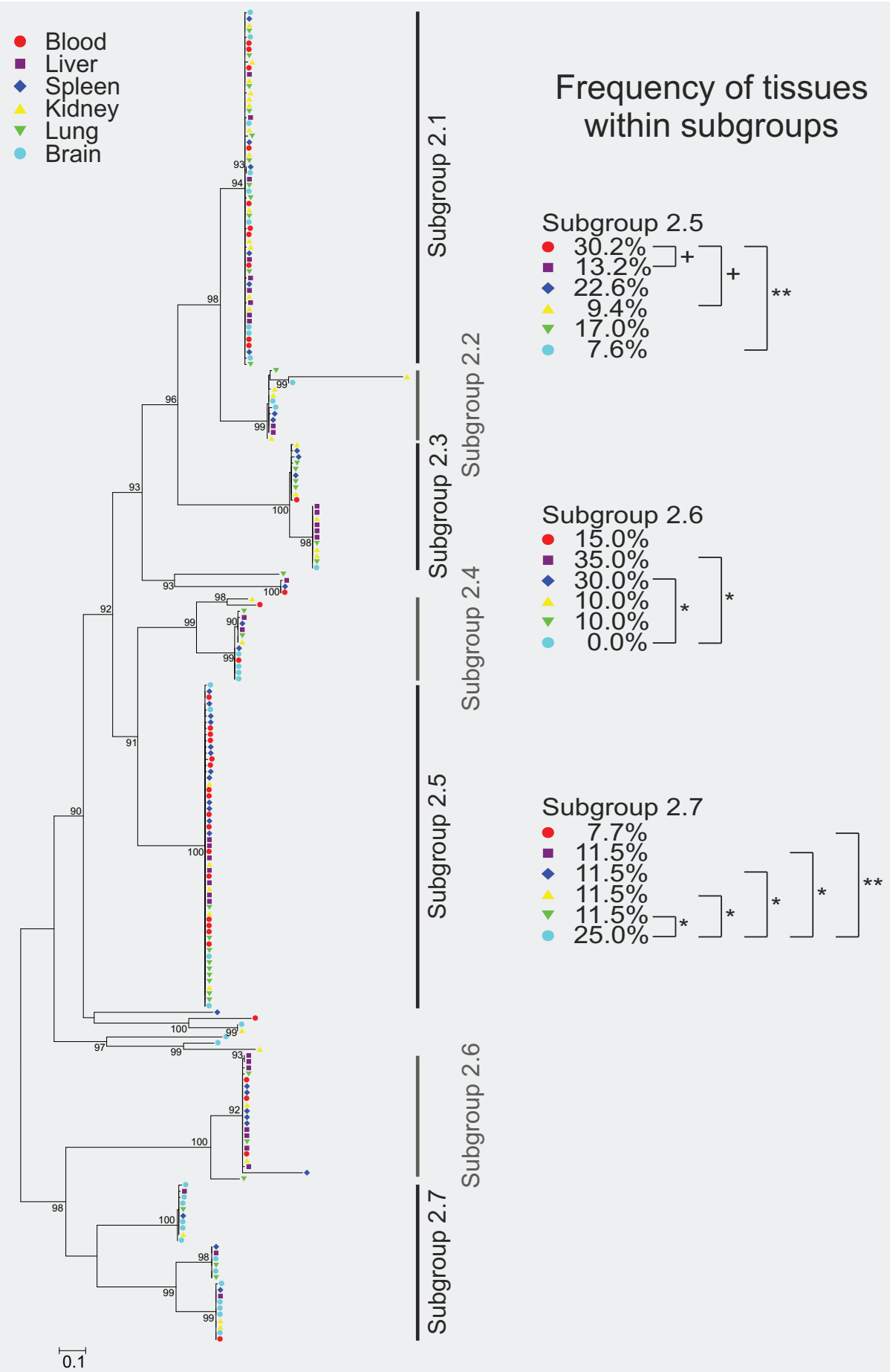

Figure 6 Phylogenetic tree representing frequency of tissues within subgroups of the cir subfamily 2. Phylogenetic tree based on maximum likelihood estimation showing 216 protein sequences deduced from cir CDNAs of subfamily 2 amplified from six different host tissues of a single female NMRI mouse infected with 100 pRBCs (parasitaemia about 30\%). The RT-PCR products for each tissue (blood, liver, spleen, kidney, lung and heart) were cloned and 36 clones from each tissue were sequenced. Statistical support is indicated as likelihood ratios only for those nodes with at least $90 \%$ support. The scale bar represents 0.1 substitutions per amino acid position. The origins of sequences (host tissues) are indicated by different colours as shown in the figure graphic legend. The cir subfamily 2 repertoire expressed here can be divided in 7 subgroups but only three of these subgroups (subgroup 2.5, 2.6, 2.7) showed significant differences of the frequency between tissues. The $p$ values were calculated by Z-test; ${ }^{* *} p<0.01 ;{ }^{*} p<0.05 ;{ }^{+} p<0.07$ ). Small (rarely occurring) subgroups of cir cDNAs were excluded from the statistical analysis. For identification of the individual sequences in each branch see Additional file 8. 


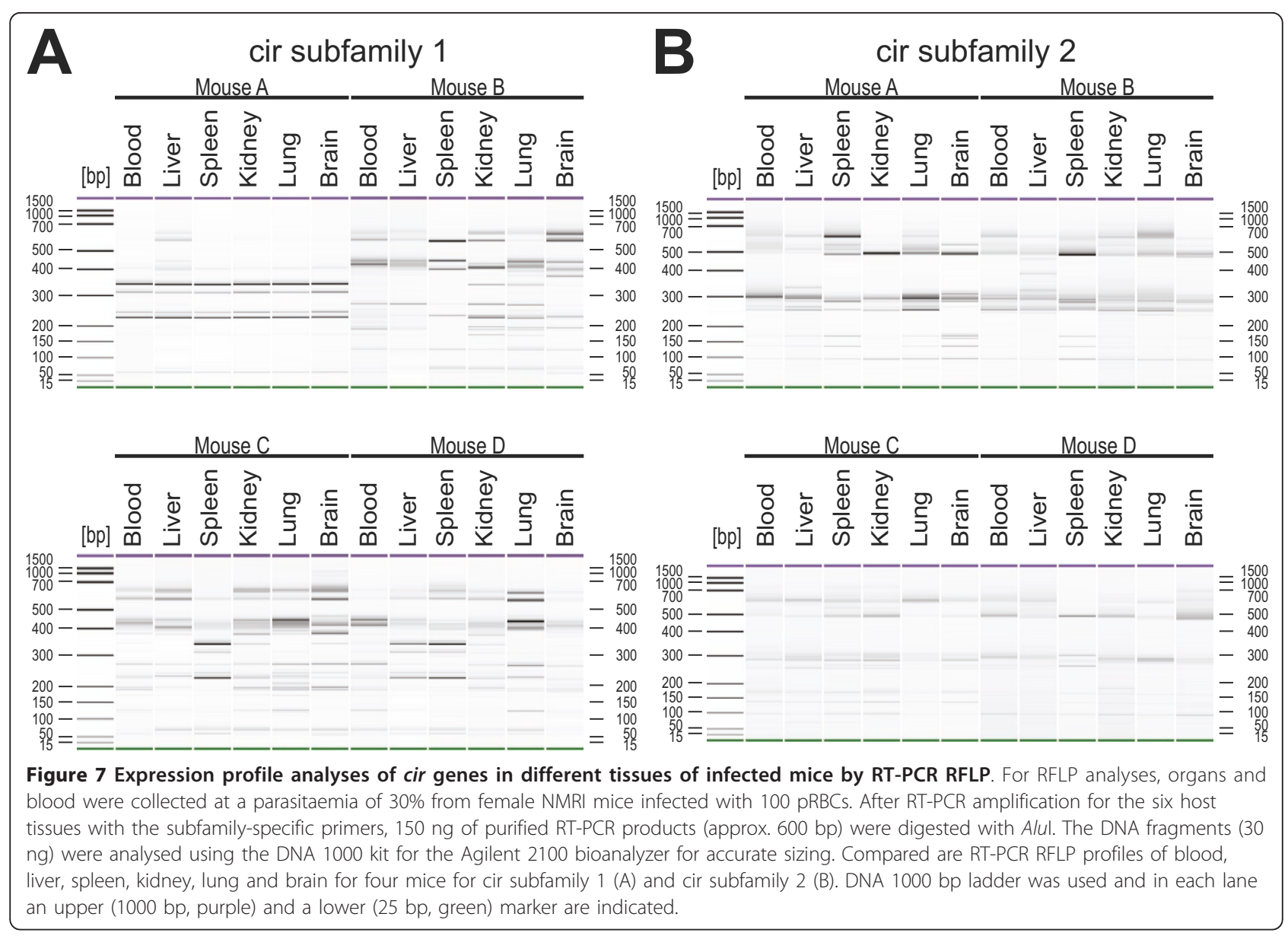

For subfamily 1, no transcriptional differences between the tissues were found in mouse A (Figure 7A). Moreover, the restriction pattern obtained for this mouse was highly different in comparison to the restriction profiles of mice B-D and the sizes of the individual fragments did not clearly refer to any in silico fragments of cir sequences obtained in the cloning study. This presence or absence of individual fragments in the RT-PCR RFLP profiles for subfamily 1 are further hints for a differential expression of cir genes in different host tissues. In particular, in mouse B, additional fragments in restriction patterns were observed e.g. in brain $(\sim 370 \mathrm{bp})$ or in kidney and lung ( $340 \mathrm{bp}$ ) which were absent from samples of all other tissues (Figure 7A). Further differences within the transcriptional profiles of cir subfamily 1 were detected e.g. in the spleen of mouse C, showing a distinct banding pattern compared to the other five tissues of the same mouse.

Differences - though generally less pronounced - were also found in cir subfamily 2 (Figure 7B). An additional fragment of $\sim 400 \mathrm{bp}$ was present e.g. in the liver of mouse B which was absent in blood, spleen kidney, lung, and brain samples from the same mouse.
Furthermore, two additional bands of cir fragments of approximately 100-200 bp appeared in the spleen of mouse B.

In conclusion, the differences in the transcriptional profiles of the different host tissues found in this experiment confirmed a correlation between parasite tissue localization on expression of specific cir genes.

\section{Expression profiling of cir genes during the course of infection}

In the blood of mice infected with 100 pRBCs, changes in the expression pattern of cir genes during the course of infection could also be detected by RT-PCR RFLP (Figure 8). The tail vein blood of mice infected i.p. with 100 pRBCs was passaged into naïve female NMRI mice at days 7 (early infection), 14 (around peak parasitaemia), 21 (7 days after peak parasitaemia) and 35 (21 days after peak parasitaemia) p.i. For analyses, blood of these passage mice was collected again at about $30 \%$ parasitaemia, i.e. just before peak parasitaemia.

Surprisingly, only two out of four immunocompetent mice (mouse 2 and 4) showed changes in expression of subfamily 1 cir genes in the blood between day 7 (early 


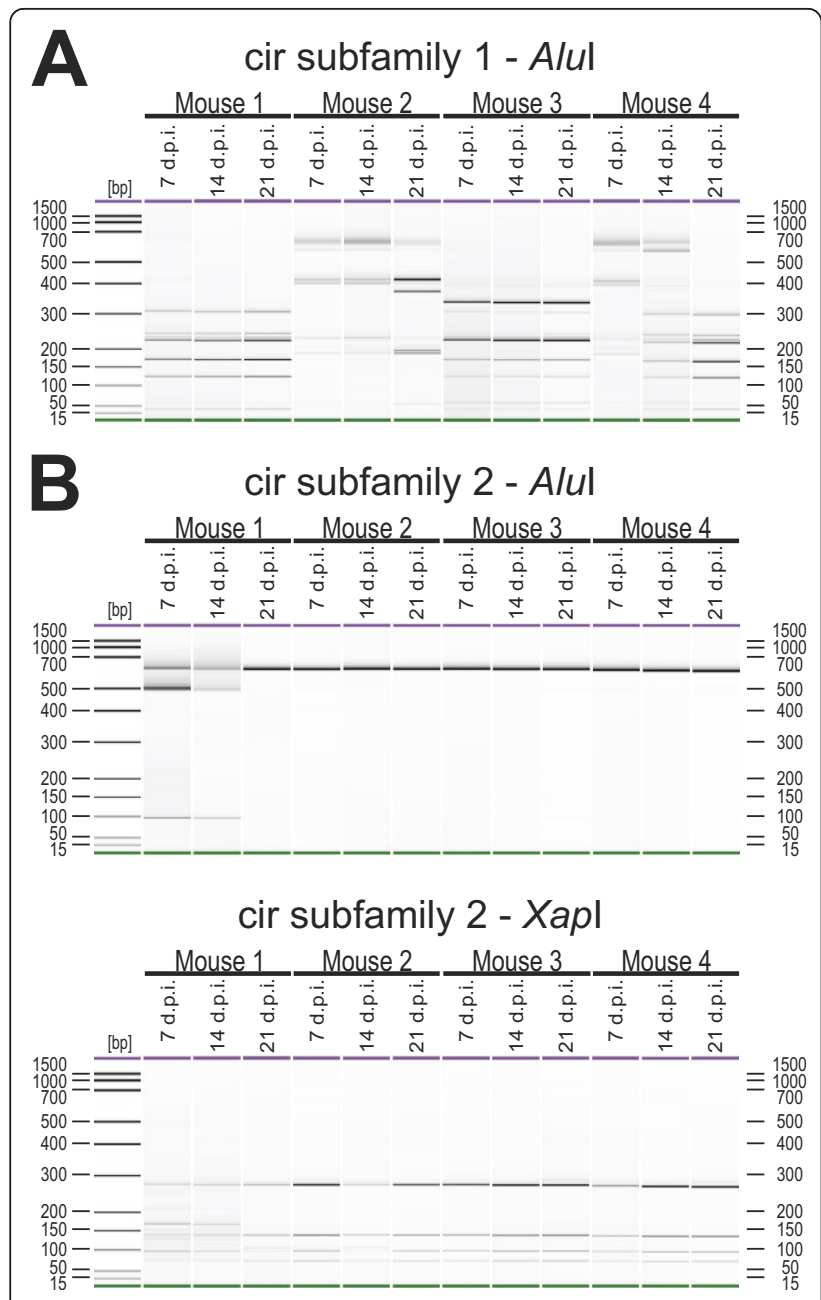

Figure 8 Transcriptional changes of cir gene expression during the course of infection. For RFLP analyses of expression changes of the cir genes during the course of infection, blood of female NMRI mice infected with 100 pRBCs were passaged on days 7, 14 and 21 days post infections (d.p.i.) into naïve female NMRI mice. Blood of these passaged mice was again collected at 30\% parasitaemia. After amplification using the subfamily-specific primers for both subfamilies, $150 \mathrm{ng}$ of purified RT-PCR products (approx. $600 \mathrm{bp}$ ) were digested with Alul and $30 \mathrm{ng}$ were then analysed using the DNA 1000 kit for the Agilent 2100 bioanalyzer. The RTPCR RFLP profiles for four mice of subfamily 1 are presented in (A). The restriction digest of subfamily 2 are shown in the upper panel of (B) where only at day 7 p.i. and day 14 p.i. of mouse 1 a few smaller restriction fragments could be detected. Therefore a second digest with Xapl for $3 \mathrm{~h}$ at $37^{\circ} \mathrm{C}$ was performed (B, lower panel). DNA 1000 bp ladder was used and in each lane an upper (1000 bp, purple) and a lower (25 bp, green) marker are indicated.

infection), day 14 (around peak parasitaemia) and day 21 (after peak parasitaemia) (Figure 8A) p.i. However, the virtually identical patterns produced here provide additional evidence for the reproducibility of the RFLP method. In mouse 2 , a completely different restriction fragment pattern was observed at day 21 p.i., seven days after peak parasitaemia, compared to the profiles of early parasitaemia (day 7 p.i.) and peak parasitaemia (day 14 p.i.). In mouse 4 the first differences in the expression pattern of the cir genes were observed already at peak parasitaemia (day 14 p.i.) and a completely changed RFLP pattern was found at day 21 p.i. (after parasitaemia) compared to day 7 p.i. in the early phase of infection. Surprisingly, however, no changes in the expression pattern could be observed for subfamily 1 in mouse 1 and 3 (Figure 8A) and for all four mice in subfamily 2 . The same RFLP pattern of amplified cir cDNAs could be identified throughout the course of an infection (Figure 8B). Since AluI did apparently not cut the cir subfamily 2 members expressed in this experiment, an additional restriction digestion with XapI was then performed (Figure $8 \mathrm{~B}$ ) confirming further that no changes in expression of cir subfamily 2 occurred in the course of an infection in these mice.

At day 35 p.i., all mice had completely resolved the infection irrespectively of changes in cir gene expression pattern before. Apparently, a chronic infection of the mice failed to occur after i.p. infection with 100 pRBC whether or not changes in cir gene expression pattern were detectable in the earlier infection.

\section{Transcriptional profiling of cir genes throughout intraerythrocytic development}

For RFLP analyses of transcriptional changes of the cir genes at different life cycle stages, $30 \mu \mathrm{l}$ tail vein blood of female NMRI mice infected with 100 pRBCs was collected at $3 \mathrm{~h}$ (early trophozoites), $10 \mathrm{~h}$ (late trophozoites) and $17 \mathrm{~h}$ (mature trophozoites and early schizonts) after beginning of the light cycle on day $13 \mathrm{p}$. i. (parasitaemia about 30\%).

For cir subfamily 1 , changes in the transcription profile could be detected in the course of a life cycle in all four mice (Figure 9A). However, these changes were much smaller than the dramatic transcriptional changes in the course of an infection which were observed for two out of four mice in Figure 8A. Only minimal changes in the fragment pattern were also observed for cir subfamily 2 . Because of the very simple and uninformative restriction fragment pattern for cir subfamily 2 cDNAs in all mice, an additional restriction digestion with XapI was again performed (Figure 9B) likewise indicating only minimal differences in the transcription pattern of cir subfamily 2 during the intraerythrocytic life cycle of $P$. chabaudi.

\section{Discussion}

In order to improve understanding of host/parasite interactions correlating antigenic variation and accumulation of parasite localization in different host tissues, expression of the P. chabaudi cir multigene family was 


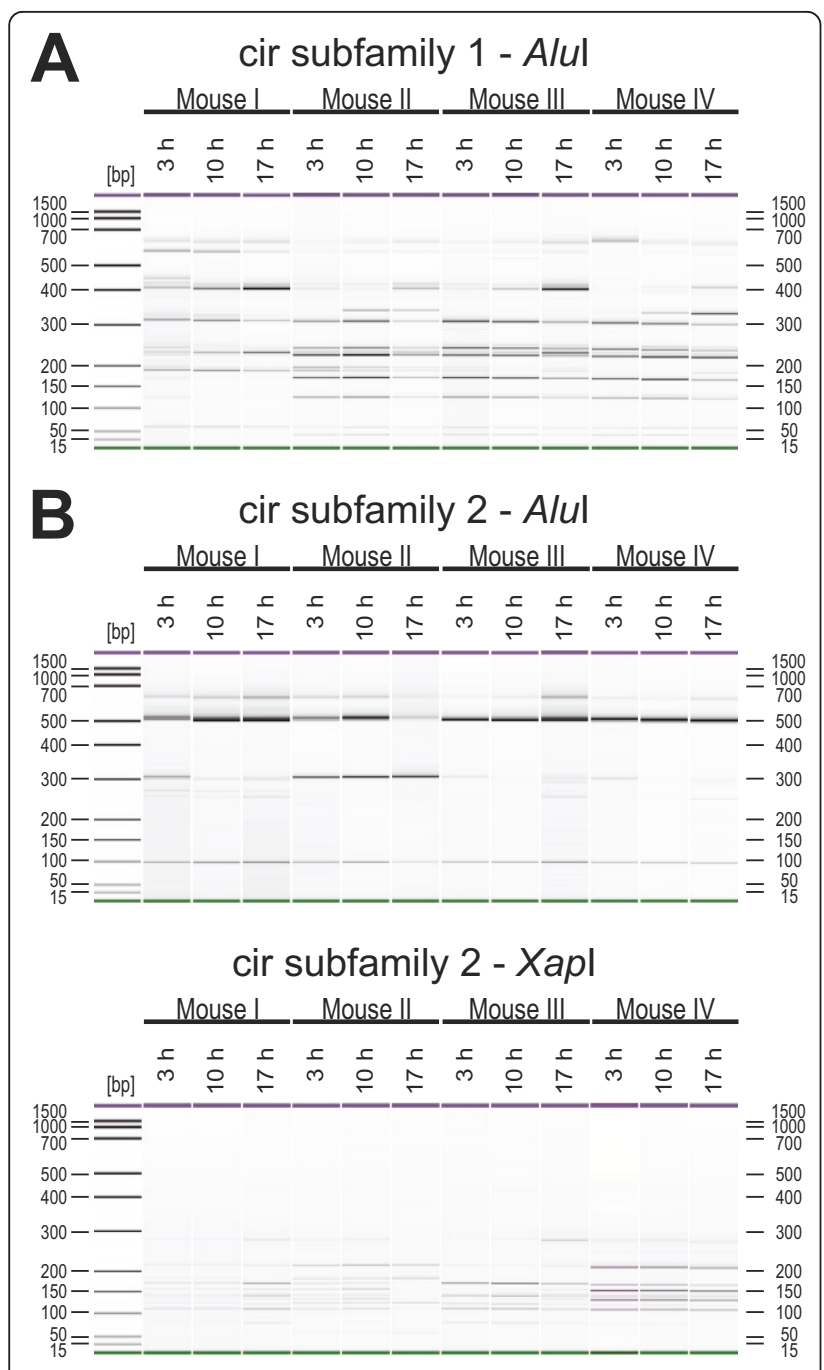

Figure 9 Transcriptional changes of cir genes during intraerythrocytic development. For expression profiling of the cir genes at three different time points in the life cycle, $30 \mu \mathrm{l}$ tail vein blood of female NMRI mice infected with 100 pRBCs were collected $3 \mathrm{~h}$ (early trophozoites), $10 \mathrm{~h}$ (late trophozoites) and $17 \mathrm{~h}$ (mature trophozoites and early schizonts) after beginning of the light cycle on day 13 p.i. (parasitaemia about 30\%). Amplification was performed using the subfamily-specific primers for both subfamilies and $150 \mathrm{ng}$ of purified RT-PCR products (approx. $600 \mathrm{bp}$ ) were digested with Alul and $30 \mathrm{ng}$ were then analysed using the DNA 1000 kit for the Agilent 2100 bioanalyzer. The RFLP profiles of subfamily 1 are shown for four mice in (A). The restriction digests of subfamily 2 are shown in the upper panel of (B). Only a few restriction fragments were detected in all samples, therefore RT-PCR products were also restricted with Xapl (B, lower panel). DNA 1000 bp ladder was used and in each lane an upper (1000 bp, purple) and a lower (25 bp, green) marker were indicated.

analysed in vivo at the transcriptional level. Despite diverse in vitro or in vivo investigations regarding antigenic variation in Plasmodium species, the complete molecular mechanism of antigenic switching in the parasites is, hitherto, far away from being fully understood. The present study, therefore, examined $P$. chabaudi infections in immunocompetent mice to get further insight in the complex phenomenon of antigenic variation and sequestration.

In an initial phylogenetic analysis of the annotated repertoire of putative CIR proteins, two subfamilies and an unassigned group of very long CIRs could be identified. While the subfamily 1 and 2 exhibit the predicted primary structure of common PIR proteins, the unassigned CIR proteins show more divergence often due to large insertions within the conserved CIR-BIR-YIR domain.

It has already previously been proposed that different subsets within the pir superfamily exhibit different functions. In P. yoelii and P. berghei, for example, a stage specific role was assumed since not all pir genes are transcribed equally when different life cycle stages were compared $[24,55]$. Indeed, different roles for P. chabaudi cir subfamily 1 (with changes in expression pattern) and subfamily 2 (with minor or no changes in expression pattern) genes are likely. The large insertions and additional transmembrane domains found within the group of unassigned CIR proteins might also be interpreted as hints for distinct functions of these proteins. Since none of them has been examined in any functional or even localization study, there is still no clue for the role these proteins might play in the Plasmodium life cycle or in the pathogens immune evasion strategy. For the VIR proteins in $P$. vivax diverse protein domain and structure predictions have been suggested to indicate different functions for different subsets of these proteins as for example those with PEXEL motif or those with additional transmembrane domains [56]. However, the presence or absence of the PEXEL motifs might simply result in usage of alternative transport signals or pathways to the host cell membrane [57] and currently no functional role has been suggested for any of the PIR proteins with more than one transmembrane domain. Since bioinformatic analysis of the CIR proteins revealed not a single strong PEXEL motif, it can be assumed that PEXEL motifs are not an important feature in the function of CIR proteins and that at least the majority of PIR proteins is able to be transported to the pRBC surface without an obvious PEXEL translocation signal.

A common ancestry of the gene families forming the pir superfamily has been postulated due to e.g. conserved sequence motifs as well as structural predictions within the PIR sequences [20]. By phylogenetic comparison of CIR and YIR proteins as performed here, this hypothesis can be further strengthened. The phylogenetic relationship of the CIR proteins with the widely studied YIRs in P. yoelii shows that the YIR protein sequences only share high similarity to CIR proteins of subfamily 2 and neither to subfamily 1 nor the group of 
unassigned CIR proteins. Comparison to the YIR antigens of the close relative $P$. yoelii suggests that most of the CIR sequences in the $P$. chabaudi genome have evolved by diversification after separation of $P$. yoelii and $P$. chabaudi from a common ancestor. Such a dispersing evolution of distinctly evolved subfamilies has also been demonstrated by phylogenetic analysis of PIR proteins encoded in $P$. yoelii and $P$. berghei genomes [52] and it is likely that the high variability of antigens in the individual malaria species distinctly evolved probably in response of the host immune pressure.

In this study a non-clonal $P$. chabaudi line very similar to the clonal P. chabaudi AS strain was used. The deduced protein sequences of the amplified cir transcripts of these parasites, however, were quite similar but not identical to the annotated putative CIR predicted from the genome sequence of the clonal $P$. chabaudi AS strain supposing a high variability of antigens even between closely related strains within the same species.

Cloning and sequencing of a first subset of cir genes demonstrated that a broad range of subfamily 1 and subfamily 2 cir genes is transcribed during a $P$. chabaudi infection in immunocompetent mice infected with a starter population of a minimal size. These findings are consistent with those described previously for other pir multigene families, e.g. the vir genes in P. vivax, the $y$ ir genes in $P$. yoelii and the bir genes in $P$. berghei $[25,26,55]$. In contrast to the mutually exclusive expression of only one var gene found in P. falciparum parasites cultured in vitro [58], it has been shown that in $P$. vivax and in several rodents Plasmodium species many different pir genes were transcribed in vivo within a parasite population in an individual host. Interestingly, examinations of natural $P$. falciparum infected human samples has shown that - in contrast to the limited transcription pattern in cultured $P$. falciparum parasites - many transcripts of var and stevor genes are also transcribed simultaneously in vivo $[59,60]$. Such contradictory in vivo and in vitro findings make clear that in vivo models such as $P$. chabaudi or other rodent malaria parasites are essential for complex investigations of antigenic variation.

In accordance with previous studies of the yir genes of P. yoelii [24], switching of cir gene expression could be detected around peak parasitaemia in the course of infection suggesting that antigenic variation might be modulated by selective forces exercised by the host immune system. However, these transcriptional changes were not observed in all infected mice and, moreover, were not detectable to the same extent for all cir subfamilies. Most marked differences in mRNA expression patterns could be observed for cir subfamily 1 whereas no or obviously less transcriptional switching was detected for cir subfamily 2 during the infection.
Completely different cir gene expression patterns of the progenies derived from $100 \mathrm{pRBCs}$ starter populations originating from the same parental population strongly suggest that a large parasite population can be extremely heterogeneous. In micromanipulated $P$. yoelii pRBCs, it has been shown that only one to three different yir transcripts were transcribed within an individual cell but many different transcripts were detected within a whole parasite population [25]. In addition, rapid switching in the transcribed repertoires of yir genes between different clonal host parasites populations and parasite developmental stages has been described. Although no infections with single pRBCs were performed in the present study, the initial diversity of parasites was apparently kept at a minimum using the minimal infectious dose resulting in patent infections by intraperitoneal infection as revealed by the substantial differences in RT-PCR RFLP patterns between mice infected with $100 \mathrm{pRBCs}$. Therefore, the number of transcribed cir genes per pRBC is presumably also much lower than that found to be transcribed in a large population.

Previous studies have analysed switching between different yir genes in P. yoelii infected mice both in immunocompetent [24] and highly immunodeficient [25] mice. Efficient and frequent switching of expressed yir genes could be observed even in the absence of any selecting force of an adaptive immune system [25]. The fact that cir gene subfamily 1 and subfamily 2 expression patterns apparently do not necessarily change in the course of a $P$. chabaudi infection in immunocompetent mice even within three weeks suggests lower on-off switching frequencies at least for these groups of cir genes. This is particularly surprising as adaptive immune responses are well known to effectively select for parasites expressing new variant antigens in other protozoan parasites [61-63].

Changes in the expression patterns of variant antigens appear to occur more frequently in cir subfamily 1 than in subfamily 2. No data are currently available for switching frequencies within the highly heterogeneous group of unassigned cir genes. Fonager et al [52] already speculated that within the yir gene family those genes belonging to highly heterogeneous groups would be more important for antigenic variation than members of more conventional subfamilies. The phylogenetic analysis including members of all previously defined yir groups [52] shows that even the most divergent YIR proteins cluster together with the CIR subfamily 2 . This suggests that subfamily 2 is ancient among the CIR proteins while subfamily 1 and the unassigned CIR proteins have probably evolved from ancient genes by diversification. The higher apparent switching frequency observed for cir subfamily 1 than subfamily 2 genes is a first 
experimental hint corroborating the hypothesis that those pir family members that evolved relatively recently might play a more prominent role for antigenic variation than those showing ancient properties [52]. Future work in both P. yoelii and P. chabaudi should, therefore, no longer neglect these unusual pir members from the analyses but should pay special attention to them.

Analysis of changes in cir gene expression patterns in the course of one asexual round of multiplication in 24 $\mathrm{h}$ revealed only minor changes in gene expression for subfamily 1 and virtually no changes for subfamily 2 . In particular, no reduction in the complexity of the cir genes in late parasite stages was observed in comparison to early rings as has been described for var genes [58]. Since Cunningham et al [25] found evidence that in $P$. yoelii even schizonts transcribe at least up to three different yir genes, a mutually exclusive expression of pir genes in late individual parasites or parasite populations appears to be highly unlikely. The same was also shown for vir genes in $P$. vivax with more than one antigen expressed in a single parasite and different expression patterns between parasites [26]. Transcriptomic analysis of $P$. vivax intraerythrocytic developmental cycle stages also revealed that many vir genes are expressed early during the ring stage and turned off later while others are expressed predominantly in schizonts [64]. These authors could not find any linkage between the position of the vir gene within the phylogenetic tree and its predominant expression time. In contrast to these results, only minor changes during the intraerythrocytic cycle were found in the present study. Possible explanations for this discrepancy include the fact that of course the RFLP analysis is less sensitive with regard to the detection of changes in expression of individual genes when compared to the microarray method used by Bozdech et al [64]. In addition, only for about $60 \%$ of the vir genes consistent temporal expression patterns could be observed for three different $P$. vivax isolates. If the highly expressed genes show no temporal expression pattern, such a pattern would clearly not be detectable with the RFLP method used here since it is not able to detect minor cir transcripts at all. Finally, the different experimental designs with only $100 \mathrm{pRBCs}$ as founders in the cir gene study and non-selected parasites from naturally infected patients for the $P$. vivax transcriptome study might well contribute to the observed differences.

Remarkable differences in the mRNA expression patterns between pRBCs in blood, liver, spleen, kidney, lung and brain could be observed suggesting a host-tissue specific expression of cir genes. It is believed that the PIR proteins, like the Pfemp1 protein family in $P$. falciparum, are possibly involved in adhesion to host receptors thus mediating accumulation and sequestration in different host tissues. For the BIR or YIR proteins, for example, an expression of these molecules on the surface of pRBCs has already been demonstrated $[24,27]$ but neither direct nor indirect evidence for a correlation of an adhesion of PIR proteins to host endothelial cells has yet been found. Accumulation of pRBCs in different tissues expressing different cir genes, however, can be considered to be a first experimental hint that CIR and maybe also other PIR proteins might indeed be involved in adhesion and sequestration. Whether rapid and dramatic changes in tissue distribution of $P$. chabaudi parasites at peak parasitaemia, i.e. exclusion from the splenic red pulp [65], has effects on cir gene expression patterns would also be interesting to analyse in the future. Since P. chabaudi is the only frequently used experimental malaria model with synchronous development and a strong sequestration phenotype, these results suggest that further studies of CIR proteins will provide important new insights into the interaction of non- $P$. falciparum malaria $\mathrm{pRBC}$ with host epithelia.

\section{Conclusions}

The present study has demonstrated for the first time that there are differences in the tissue-specific expression of some cir genes. These results suggest a possible correlation between the expression of CIR antigens and accumulation of parasites in inner organs of the host. The high agreement in results obtained for transcriptional switching and antigenic variation of the cir genes with that for other members of the pir superfamily indicate very well that the cir genes are promising candidates for further functional studies. For example parasites expressing certain CIRs constitutively as transgenes might improve understanding of the functional role of the pir superfamily in Plasmodium infections.

\section{Additional material}

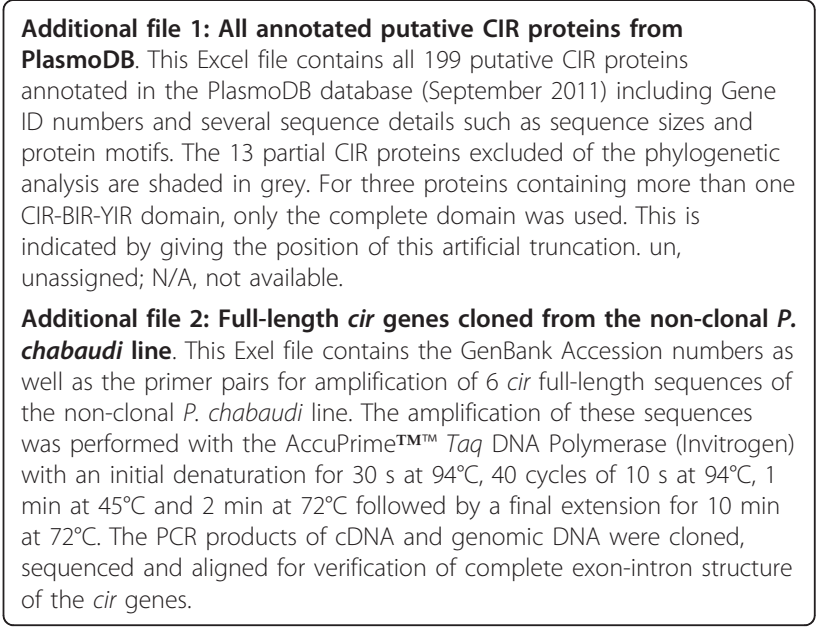


Additional file 3: Phylogenetic tree of 186 annotated CIR and selected YIR proteins in Newick format. This text file contains the phylogenetic maximum likelihood tree of the 186 annotated CIR and selected YIR proteins in Newick format including Gene ID numbers and maximum likelihood ratios as statistical support at the nodes.

Additional file 4: Splice variant of cir gene found by RT-PCR and genomic PCR. The PDF file shows the alignment of two cir transcripts amplified by RT-PCR with their corresponding genomic DNA sequence. The first cir transcript shows the common cir gene structure with three exons. The second cir transcript, in contrast, represents a splice variant in which the usual start codon is eliminated resulting in an $\mathrm{NH}_{2}$-terminally truncated protein. Start codons and stop codons are highlighted in green and red, respectively. The coding exons are colour shaded in blue and the primer sequences are highlighted in yellow.

Additional file 5: The amplified repertoire of cir CDNAs of the cloning study. In this Excel file all amplified cir CDNAs of the cloning study are given with their GenBank ${ }^{\mathbb{B}_{\circledast}}$ Accession numbers. The cir cDNAs are sorted according to their subgroups. The origin of sequences (host tissues) is highlighted by colours: Blood (red), liver (purple), spleen (blue), kidney (yellow) and brain (cyan).

Additional file 6: Phylogenetic relationship of protein sequences deduced from the cloning study with the PlasmoDB CIR domains. This PDF file shows the phylogenetic maximum likelihood tree of the 186 putative conserved domains of CIRs and the 190 deduced CIR protein sequences of the cloning and sequencing study. The cir subfamily 1 and subfamily 2 are highlighted in purple and cyan, respectively. The deduced CIR protein sequences of the cloning and sequencing study are highlighted with dots in the subfamily-specific colour.

Additional file 7: Newick format of the phylogenetic tree of cir subfamily 1 . This text file contains the phylogenetic maximum likelihood tree of the deduced proteins from 216 cDNAs of cir subfamily 1 in Newick format. The individual names for each sequence are indicated.

Additional file 8: Newick format of the phylogenetic tree of cir subfamily 2 . This text file contains the phylogenetic maximum likelihood tree of the deduced proteins from 216 cDNAs of cir subfamily 2 in Newick format. The individual names for each sequence are indicated.

Additional file 9: In silico restriction of the amplified cir CDNAs of the cloning study. The fragment sizes of the restricted CDNAs sequences of the cloning study, in silico digested with Alul and Xapl, were shown in this Excel file. In the first table sheet the restriction fragments of the cir CDNAs of subfamily 1 were listed, in the second table sheet of subfamily 2 , respectively. The tissue origins of sequences are highlighted by colours: Blood (red), liver (purple), spleen (blue), kidney (yellow) and brain (cyan). The cir cDNA sequences are sorted according the subgroups.

\section{Acknowledgements}

This study was supported by a research grant from the Deutsche Forschungsgemeinschaft (DFG) (KR 2245/5-1). The authors thank Georg von Samson-Himmelstjerna and Janina Demeler for support and critical revision of the manuscript.

\section{Authors' contributions}

JK designed the study, planned and supervised all experiments. PE performed the experiments. JK and PE did bioinformatic and statistical analyses and wrote the manuscript. All authors read and approved the final version.

\section{Competing interests}

The authors declare that they have no competing interests.

Received: 14 June 2011 Accepted: 19 September 2011 Published: 19 September 2011

\section{References}

1. Brown KN, Brown IN: Immunity to malaria: antigenic variation in chronic infections of Plasmodium knowlesi. Nature 1965, 208:1286-1288.

2. McLean SA, Pearson CD, Phillips RS: Plasmodium chabaudi: antigenic variation during recrudescent parasitaemias in mice. Exp Parasitol 1982, 54:296-302.

3. Barnwell JW, Howard RJ, Miller LH: Altered expression of Plasmodium knowlesi variant antigen on the erythrocyte membrane in splenectomized rhesus monkeys. J Immunol 1982, 128:224-226.

4. Mendis KN, Ihalamulla RI, David PH: Diversity of Plasmodium vivax-induced antigens on the surface of infected human erythrocytes. Am J Trop Med Hyg 1988, 38:42-46.

5. Franke-Fayard B, Fonager J, Braks A, Khan SM, Janse CJ: Sequestration and tissue accumulation of human malaria parasites: can we learn anything from rodent models of malaria? PLOS Pathog 2010, 6.

6. Miller LH, Baruch DI, Marsh K, Doumbo OK: The pathogenic basis of malaria. Nature 2002, 415:673-679.

7. Mackintosh $\mathrm{CL}$, Beeson JG, Marsh K: Clinical features and pathogenesis of severe malaria. Trends Parasitol 2004, 20:597-603.

8. Rasti N, Wahlgren M, Chen Q: Molecular aspects of malaria pathogenesis. FEMS Immunol Med Microbiol 2004, 41:9-26.

9. Su XZ, Heatwole VM, Wertheimer SP, Guinet F, Herrfeldt JA, Peterson DS, Ravetch JA, Wellems TE: The large diverse gene family var encodes proteins involved in cytoadherence and antigenic variation of Plasmodium falciparum-infected erythrocytes. Cell 1995, 82:89-100.

10. Dzikowski $R$, Templeton TJ, Deitsch $\mathrm{K}$ : Variant antigen gene expression in malaria. Cell Microbiol 2006, 8:1371-1381.

11. Deitsch KW, Calderwood MS, Wellems TE: Malaria. Cooperative silencing elements in var genes. Nature 2001, 412:875-876

12. Voss TS, Healer J, Marty AJ, Duffy MF, Thompson JK, Beeson JG, Reeder JC, Crabb BS, Cowman AF: A var gene promoter controls allelic exclusion of virulence genes in Plasmodium falciparum malaria. Nature 2006, 439:1004-1008.

13. Recker M, Buckee CO, Serazin A, Kyes S, Pinches R, Christodoulou Z Springer AL, Gupta S, Newbold Cl: Antigenic variation in Plasmodium falciparum malaria involves a highly structured switching pattern. PLOS Pathog 2011, 7:e1001306.

14. Deitsch KW, Moxon ER, Wellems TE: Shared themes of antigenic variation and virulence in bacterial, protozoal, and fungal infections. Microbiol Mol Biol Rev 1997, 61:281-293.

15. Fischer K, Chavchich M, Huestis R, Wilson DW, Kemp DJ, Saul A: Ten families of variant genes encoded in subtelomeric regions of multiple chromosomes of Plasmodium chabaudi, a malaria species that undergoes antigenic variation in the laboratory mouse. Mol Microbiol 2003, 48:1209-1223.

16. al-Khedery B, Barnwell JW, Galinski MR: Antigenic variation in malaria: a 3' genomic alteration associated with the expression of a $P$. knowlesi variant antigen. Mol Cell 1999, 3:131-141.

17. Carlton JM, Angiuoli SV, Suh BB, Kooij TW, Pertea M, Silva JC, Ermolaeva MD, Allen JE, Selengut JD, Koo HL, Peterson JD, Pop M, Kosack DS, Shumway MF, Bidwell SL, Shallom SJ, van Aken SE, Riedmuller SB, Feldblyum TV, Cho JK, Quackenbush J, Sedegah M, Shoaibi A, Cummings LM, Florens L, Yates JR, Raine JD, Sinden RE, Harris MA, Cunningham DA, Preiser PR, Bergman LW, Vaidya AB, van Lin $L H_{1}$ Janse CJ, Waters AP, Smith HO, White OR, Salzberg SL, Venter JC, Fraser CM, Hoffman SL, Gardner MJ, Carucci DJ: Genome sequence and comparative analysis of the model rodent malaria parasite Plasmodium yoelii yoelii. Nature 2002, 419:512-519.

18. Korir CC, Galinski MR: Proteomic studies of Plasmodium knowlesi SICA variant antigens demonstrate their relationship with $P$. falciparum EMP1. Infect Genet Evol 2006, 6:75-79.

19. Bull PC, Buckee CO, Kyes S, Kortok MM, Thathy V, Guyah B, Stoute JA, Newbold Cl, Marsh K: Plasmodium falciparum antigenic variation. Mapping mosaic var gene sequences onto a network of shared, highly polymorphic sequence blocks. Mol Microbiol 2008, 68:1519-1534.

20. Janssen CS, Phillips RS, Turner CM, Barrett MP: Plasmodium interspersed repeats: the major multigene superfamily of malaria parasites. Nucleic Acids Res 2004, 32:5712-5720.

21. Cunningham D, Lawton J, Jarra W, Preiser P, Langhorne J: The pir multigene family of Plasmodium: antigenic variation and beyond. $\mathrm{Mo}$ Biochem Parasitol 2010, 170:65-73. 
22. del Portillo HA, Fernandez-Becerra C, Bowman S, Oliver K, Preuss M, Sanchez CP, Schneider NK, Villalobos JM, Rajandream MA, Harris D, Pereira da Silva LH, Barrell B, Lanzer M: A superfamily of variant genes encoded in the subtelomeric region of Plasmodium vivax. Nature 2001, 410:839-842.

23. Janssen CS, Barrett MP, Turner CM, Phillips RS: A large gene family for putative variant antigens shared by human and rodent malaria parasites. Proc Biol Sci 2002, 269:431-436.

24. Cunningham DA, Jarra W, Koernig S, Fonager J, Fernandez-Reyes D, Blythe JE, Waller C, Preiser PR, Langhorne J: Host immunity modulates transcriptional changes in a multigene family (yir) of rodent malaria. $\mathrm{Mol}$ Microbiol 2005, 58:636-647.

25. Cunningham D, Fonager J, Jarra W, Carret C, Preiser P, Langhorne J: Rapid changes in transcription profiles of the Plasmodium yoelii yir multigene family in clonal populations: lack of epigenetic memory? PLoS One 2009, 4:e4285.

26. Fernandez-Becerra C, Pein O, de Oliveira TR, Yamamoto MM, Cassola AC, Rocha C, Soares IS, de Braganca Pereira CA, del Portillo HA: Variant proteins of Plasmodium vivax are not clonally expressed in natural infections. Mol Microbiol 2005, 58:648-658.

27. Di Girolamo F, Raggi C, Birago C, Pizzi E, Lalle M, Picci L, Pace T, Bachi A, de Jong J, Janse CJ, Waters AP, Sargiacomo M, Ponzi M: Plasmodium lipid rafts contain proteins implicated in vesicular trafficking and signalling as well as members of the PIR superfamily, potentially implicated in host immune system interactions. Proteomics 2008, 8:2500-2513.

28. Sherman IW, Eda S, Winograd E: Cytoadherence and sequestration in Plasmodium falciparum: defining the ties that bind. Microbes Infect 2003, 5:897-909.

29. del Portillo HA, Lanzer M, Rodriguez-Malaga S, Zavala F, FernandezBecerra C: Variant genes and the spleen in Plasmodium vivax malaria. Int J Parasitol 2004, 34:1547-1554.

30. Carvalho BO, Lopes SC, Nogueira PA, Orlandi PP, Bargieri DY, Blanco YC, Mamoni R, Leite JA, Rodrigues MM, Soares IS, Oliveira TR, Wunderlich G, Lacerda MV, del Portillo HA, Araujo MO, Russell B, Suwanarusk R, Snounou G, Renia L, Costa FT: On the cytoadhesion of Plasmodium vivaxinfected erythrocytes. J Infect Dis 2010, 202:638-647.

31. Franke-Fayard B, Janse CJ, Cunha-Rodrigues M, Ramesar J, Buscher P, Que I, Lowik C, Voshol PJ, den Boer MA, van Duinen SG, Febbraio M, Mota MM, Waters AP: Murine malaria parasite sequestration: CD36 is the major receptor, but cerebral pathology is unlinked to sequestration. Proc Natl Acad Sci USA 2005, 102:11468-11473.

32. Spaccapelo R, Janse CJ, Caterbi S, Franke-Fayard B, Bonilla JA, Syphard LM, Di Cristina M, Dottorini T, Savarino A, Cassone A, Bistoni F, Waters AP, Dame JB, Crisanti A: Plasmepsin 4-deficient Plasmodium berghei are virulence attenuated and induce protective immunity against experimental malaria. Am J Pathol 2010, 176:205-217.

33. Neres R, Marinho CR, Goncalves LA, Catarino MB, Penha-Goncalves C: Pregnancy outcome and placenta pathology in Plasmodium berghei ANKA infected mice reproduce the pathogenesis of severe malaria in pregnant women. PLoS One 2008, 3:e1608.

34. Marinho CR, Neres R, Epiphanio S, Goncalves LA, Catarino MB, PenhaGoncalves C: Recrudescent Plasmodium berghei from pregnant mice displays enhanced binding to the placenta and induces protection in multigravida. PLoS One 2009, 4:e5630.

35. Mota MM, Jarra W, Hirst E, Patnaik PK, Holder AA: Plasmodium chabaudiinfected erythrocytes adhere to CD36 and bind to microvascular endothelial cells in an organ-specific way. Infect Immun 2000, 68:4135-4144.

36. Aurrecoechea C, Brestelli J, Brunk BP, Dommer J, Fischer S, Gajria B, Gao X, Gingle A, Grant G, Harb OS, Heiges M, Innamorato F, lodice J, Kissinger JC, Kraemer E, Li W, Miller JA, Nayak V, Pennington C, Pinney DF, Roos DS, Ross C, Stoeckert CJ Jr, Treatman C, Wang H: PlasmoDB: a functional genomic database for malaria parasites. Nucleic Acids Res 2009, 37: D539-543.

37. Marchler-Bauer A, Anderson JB, Chitsaz F, Derbyshire MK, DeWeese-Scott C, Fong JH, Geer LY, Geer RC, Gonzales NR, Gwadz M, He S, Hurwitz DI, Jackson JD, Ke Z, Lanczycki CJ, Liebert CA, Liu C, Lu F, Lu S, Marchler GH, Mullokandov M, Song JS, Tasneem A, Thanki N, Yamashita RA, Zhang D, Zhang N, Bryant SH: CDD: specific functional annotation with the Conserved Domain Database. Nucleic Acids Res 2009, 37:D205-210.
38. Marchler-Bauer A, Bryant SH: CD-Search: protein domain annotations on the fly. Nucleic Acids Res 2004, 32:W327-331.

39. Marchler-Bauer A, Lu S, Anderson JB, Chitsaz F, Derbyshire MK, DeWeeseScott C, Fong JH, Geer LY, Geer RC, Gonzales NR, Gwadz M, Hurwitz DI, Jackson JD, Ke Z, Lanczycki CJ, Lu F, Marchler GH, Mullokandov M, Omelchenko MV, Robertson CL, Song JS, Thanki N, Yamashita RA, Zhang D, Zhang N, Zheng C, Bryant SH: CDD: a Conserved Domain Database for the functional annotation of proteins. Nucleic Acids Res 2011, 39:D225-229.

40. Larkin MA, Blackshields G, Brown NP, Chenna R, McGettigan PA, McWilliam H, Valentin F, Wallace IM, Wilm A, Lopez R, Thompson JD, Gibson TJ, Higgins DG: Clustal W and Clustal $\times$ version 2.0. Bioinformatics 2007, 23:2947-2948.

41. Guindon S, Gascuel O: A simple, fast, and accurate algorithm to estimate large phylogenies by maximum likelihood. Syst Biol 2003, 52:696-704.

42. Jones DT, Taylor WR, Thornton JM: The rapid generation of mutation data matrices from protein sequences. Comput Appl Biosci 1992, 8:275-282.

43. Tamura K, Dudley J, Nei M, Kumar S: MEGA4: Molecular Evolutionary Genetics Analysis (MEGA) software version 4.0. Mol Biol Evol 2007, 24:1596-1599.

44. Kumar S, Nei M, Dudley J, Tamura K: MEGA: a biologist-centric software for evolutionary analysis of DNA and protein sequences. Brief Bioinform 2008, 9:299-306.

45. Kyte J, Doolittle RF: A simple method for displaying the hydropathic character of a protein. J Mol Biol 1982, 157:105-132.

46. Jones DT, Taylor WR, Thornton JM: A model recognition approach to the prediction of all-helical membrane protein structure and topology. Biochemistry 1994, 33:3038-3049.

47. Krogh A, Larsson B, von Heijne G, Sonnhammer EL: Predicting transmembrane protein topology with a hidden Markov model: application to complete genomes. J Mol Biol 2001, 305:567-580.

48. Emanuelsson O, Brunak S, von Heijne G, Nielsen H: Locating proteins in the cell using TargetP, SignalP and related tools. Nat Protoc 2007, 2:953-971.

49. Wunderlich F, Stubig H, Konigk E: Development of Plasmodium chabaudi in mouse red blood cells: structural properties of the host and parasite membranes. J Protozool 1982, 29:60-66.

50. Wunderlich F, Dkhil MA, Mehnert LI, Braun JV, El-Khadragy M, Borsch E, Hermsen D, Benten WP, Pfeffer K, Mossmann H, Krücken J: Testosterone responsiveness of spleen and liver in female lymphotoxin beta receptordeficient mice resistant to blood-stage malaria. Microbes Infect 2005, 7:399-409.

51. Krücken J, Delic D, Pauen H, Wojtalla A, El-Khadragy M, Dkhil MA, Mossmann H, Wunderlich F: Augmented particle trapping and attenuated inflammation in the liver by protective vaccination against Plasmodium chabaudi malaria. Malar J 2009, 8:54.

52. Fonager J, Cunningham D, Jarra W, Koernig S, Henneman AA, Langhorne J, Preiser P: Transcription and alternative splicing in the yir multigene family of the malaria parasite Plasmodium y. yoelii: identification of motifs suggesting epigenetic and post-transcriptional control of RNA expression. Mol Biochem Parasitol 2007, 156:1-11.

53. Marti M, Good RT, Rug M, Knuepfer E, Cowman AF: Targeting malaria virulence and remodeling proteins to the host erythrocyte. Science 2004, 306:1930-1933.

54. Hiss JA, Przyborski JM, Schwarte F, Lingelbach K, Schneider G: The Plasmodium export element revisited. PLoS One 2008, 3:e1560.

55. Hall N, Karras M, Raine JD, Carlton JM, Kooij TW, Berriman M, Florens L, Janssen CS, Pain A, Christophides GK, James K, Rutherford K, Harris B, Harris D, Churcher C, Quail MA, Ormond D, Doggett J, Trueman HE, Mendoza J, Bidwell SL, Rajandream MA, Carucci DJ, Yates JR, Kafatos FC, Janse CJ, Barrell B, Turner CM, Waters AP, Sinden RE: A comprehensive survey of the Plasmodium life cycle by genomic, transcriptomic, and proteomic analyses. Science 2005, 307:82-86.

56. Merino EF, Fernandez-Becerra C, Durham AM, Ferreira JE, Tumilasci VF, d'Arc-Neves J, da Silva-Nunes M, Ferreira MU, Wickramarachchi T, UdagamaRandeniya P, Handunnetti SM, Del Portillo HA: Multi-character population study of the vir subtelomeric multigene superfamily of Plasmodium vivax, a major human malaria parasite. Mol Biochem Parasitol 2006, 149:10-16.

57. Spielmann T, Gilberger TW: Protein export in malaria parasites: do multiple export motifs add up to multiple export pathways? Trends Parasitol 2010, 26:6-10. 
58. Scherf A, Hernandez-Rivas R, Buffet P, Bottius E, Benatar C, Pouvelle B, Gysin J, Lanzer M: Antigenic variation in malaria: in situ switching, relaxed and mutually exclusive transcription of var genes during intraerythrocytic development in Plasmodium falciparum. EMBO J 1998, 17:5418-5426.

59. Daily JP, Le Roch KG, Sarr O, Fang X, Zhou Y, Ndir O, Mboup S, Sultan A, Winzeler EA, Wirth DF: In vivo transcriptional profiling of Plasmodium falciparum. Malar J 2004, 3:30.

60. Daily JP, Le Roch KG, Sarr O, Ndiaye D, Lukens A, Zhou Y, Ndir O, Mboup S, Sultan A, Winzeler EA, Wirth DF: In vivo transcriptome of Plasmodium falciparum reveals overexpression of transcripts that encode surface proteins. J Infect Dis 2005, 191:1196-1203.

61. Lopez-Rubio JJ, Riviere L, Scherf A: Shared epigenetic mechanisms control virulence factors in protozoan parasites. Curr Opin Microbiol 2007, 10:560-568.

62. Zambrano-Villa S, Rosales-Borjas D, Carrero JC, Ortiz-Ortiz L: How protozoan parasites evade the immune response. Trends Parasitol 2002, 18:272-278.

63. Vanhamme L, Pays E, McCulloch R, Barry JD: An update on antigenic variation in African trypanosomes. Trends Parasitol 2001, 17:338-343.

64. Bozdech Z, Mok S, Hu G, Imwong M, Jaidee A, Russell B, Ginsburg H, Nosten F, Day NP, White NJ, Carlton JM, Preiser PR: The transcriptome of Plasmodium vivax reveals divergence and diversity of transcriptional regulation in malaria parasites. Proc Natl Acad Sci USA 2008, 105:16290-16295.

65. Krücken J, Mehnert LI, Dkhil MA, El-Khadragy M, Benten WP, Mossmann H, Wunderlich F: Massive destruction of malaria-parasitized red blood cells despite spleen closure. Infect Immun 2005, 73:6390-6398.

doi:10.1186/1475-2875-10-272

Cite this article as: Ebbinghaus and Krücken: Characterization and tissuespecific expression patterns of the Plasmodium chabaudi cir multigene family. Malaria Journal 2011 10:272.

\section{Submit your next manuscript to BioMed Central and take full advantage of:}

- Convenient online submission

- Thorough peer review

- No space constraints or color figure charges

- Immediate publication on acceptance

- Inclusion in PubMed, CAS, Scopus and Google Scholar

- Research which is freely available for redistribution

Submit your manuscript at www.biomedcentral.com/submit 